\title{
Dimethylsulfoniopropionate (DMSP) and dimethylsulfide (DMS) sea surface distributions simulated from a global three-dimensional ocean carbon cycle model
}

\author{
Olivier Aumont, ${ }^{1}$ Sauveur Belviso, and Patrick Monfray \\ Laboratoire des Sciences du Climat et de l'Environnement, Gif-sur-Yvette, France \\ Received 18 October 1999; revised 8 September 2000; accepted 8 February 2001; published 24 April 2002.
}

[1] A global model for surface dimethylsulfide (DMS) and particulate dimethylsulfoniopropionate (DMSP) (pDMS) distributions is presented. The main goals of this work were to be able to predict the regional distribution of the air-sea fluxes of DMS and to predict eventually their future evolution with climate change. Diagnostic relationships have been established from data sets obtained during the ALBATROSS and EUMELI cruises carried out in the Atlantic Ocean. These equations nonlinearly relate DMS and pDMSP concentrations to chlorophyll concentrations and to the trophic status of surface waters. This model has been embedded in the global ocean carbon cycle model Institut Pierre et Simon Laplace-Ocean Carbon Cycle Model version 2 (ISPL-OCCM2), a simple plankton model coupled to a global three-dimensional ocean general circulation model. Predicted global distributions and seasonal variations of surface chlorophyll are in good agreement with the observations, except in the equatorial Pacific Ocean and, to a lesser extent, in the Southern Ocean. In these regions, simulated surface chlorophyll concentrations are strongly overestimated, most likely because limitations of the biological production by nutrients like iron or silicate are not considered. The model predicts surface DMS and pDMSP concentrations, which compare reasonably well with the observations. However, in the high latitudes, seasonal variations are underestimated, especially in the Ross and Weddell Seas where observed very elevated concentrations of DMS due to spring and summer blooms of Phaeocystis cannot be reproduced by the model. The global annual flux of DMS predicted by IPSL-OCCM2 ranges from 17 to $26.7 \mathrm{Tg} \mathrm{S}$ $\mathrm{yr}^{-1}$ depending on the formulation for gas exchange coefficient. About one third of this flux is located in the subtropical/subpolar frontal zone of the Southern Ocean, which plays a critical role in the sulfur cycle. Furthermore, model results suggest that the Southern Ocean, south of the Polar Front, could be a rather modest source of DMS for the atmosphere. INDEX TERMS: 4203 Oceanography: General: Analytical modeling; 4805 Oceanography: Biological and Chemical: Biogeochemical cycles (1615); 4842 Oceanography: Biological and Chemical: Modeling; 0305 Atmospheric Composition and Structure: Aerosols and particles (0345, 4801); KEYWORDS: ocean, biogeochemistry, ecosystem modeling, DMS, global

\section{Introduction}

[2] Dimethylsulfide (DMS) is an important sulfur compound produced naturally in the sea by the phytoplankton from a precursor compound dimethylsulfoniopropionate (DMSP). DMS is present in the seawater at sufficient concentrations to sustain a large flux to the atmosphere, estimated to $16-50 \mathrm{Tg} \mathrm{S} \mathrm{yr}^{-1}$ [Bates et al., 1987; Andreae, 1990; Erickson et al., 1990]. Once in the atmosphere, it is photooxydized to form non-sea salt sulphate aerosols particles that affect the climate directly by backscattering the solar radiation and indirectly as cloud condensation nuclei. It has been postulated that the planet's climate may be modulated by variations in DMS production resulting from changes of sea surface temperature and solar radiation [Nguyen et al., 1983; Charlson et al., 1987]. However, this precise feedback loop is yet to be understood.

[3] A major limitation to our understanding of the role of the natural sulfur cycle results from the large uncertainties on the

\footnotetext{
${ }^{1}$ Now at Laboratoire d'Oceanographie Dynamique et de Climatologie Paris, France.

Copyright 2002 by the American Geophysical Union. 0148-0227/02/1999JC000111
}

magnitude of the ocean source of DMS and its variability. The estimates vary by a factor of $2-3$. To improve these estimates, analyses of DMS in surface marine waters have been carried out extensively in the past 2 decades. The data have then been organized by major biogeographic regions of the world ocean [Andreae et al., 1985] or as a function of latitude, longitude, and season [Bates et al., 1987]. More recently, global seasonal maps of DMS have been constructed by means of objective analysis [Kettle et al., 1999]. In the latter case an inventory of over 15,600 DMS measurements has been realized. However, many regions, especially in the Southern Ocean, are still too undersampled to infer precisely their importance in the sulfur cycle.

[4] The three-dimensional atmospheric models used to simulate the global tropospheric distributions of sulfur compounds include inventories of DMS marine emissions, which are computed as a product of sea-to-air transfer velocity and seawater DMS concentrations [Feichter et al., 1996; Chin et al., 1996]. Alternatively, they use the empirical relations by Bates et al. [1987], which relate DMS flux to solar radiation [Erickson et al., 1990; Pham et al., 1995]. Because neither approach includes a description of the biogenic origin of DMS, the response of the marine source of DMS to a climatic perturbation can presently be assessed in a climate model only through its impact on the solar irradiance and on the sea-to-air transfer velocity, which mainly varies with temperature 
and wind velocity [Liss and Merlivat, 1986; Wanninkhof, 1992]. However, parameterizing the processes that control DMS production and removal is far from straightforward. Simple parameterizations to assess the large-scale variability of DMS concentrations in the sea directly by linear regressions from biological variables such as Chl $a$ or particulate DMSP (pDMSP) concentrations, although statistically significant, account for only $10-30 \%$ of DMS variability [Kettle et al., 1999]. This limits their use in today's climate models and their ability to assess the hypothesized feedback link whereby climate affects the level of DMS emissions.

[5] Lawrence [1993] has proposed an empirical model of the feedbacks between the DMS cycle and climate. This model includes biological aspects of the production and removal of DMS based on phytoplankton growth and zooplankton grazing. He estimated the feedback strength to be about 20\% (10-50\%) of that which would be necessary to counteract completely a perturbation to global climate due to the accumulation of anthropogenic gases. Such parameterizations of DMS production have been incorporated into one-dimensional (1-D) or regional models [Gabric et al., 1993]. However, these parameterizations are not yet suitable for global ocean models mainly because they increase computing time and cost markedly. The work of Gabric et al. [1998] is a preliminary step toward the use of general circulation models together with DMS production models to investigate the impact of simulated climate change on the air-sea flux of DMS.

[6] In this paper a model of the global distribution of sea surface DMS concentrations is presented. The DMS parameterization we propose derives from DMS surveys carried out in contrasted areas of the world oceans. They are based on nonlinear relationships that relate DMS and pDMSP concentrations to the $\mathrm{Chl} a$ content and to the trophic status of the surface waters. The latter parameters are estimated from an ocean carbon cycle model (OCCM). The model predictions are then evaluated with pDMSP and DMS observations obtained from the literature.

\section{Models}

[7] The model of DMS and pDMSP is based on the 3-D ocean carbon cycle model Institut Pierre et Simon Laplace-Ocean Carbon Cycle Model version 2 (ISPL-OCCM2). In this model the carbon cycle is simulated by the biogeochemical model Phosphate-Phytoplankton-POC-Zooplankton-DOC (P3ZD), [Aumont, 1998], which is embedded in a tracer transport version of the ocean general circulation model (OGCM) Ocean Parallélisé (OPA) [Delecluse et al., 1993]. Here we outline the important aspects of both the physical and biogeochemical models.

\subsection{Ocean General Circulation Model}

[8] The carbon cycle model used here is based on a tracer transport version of the global-scale OGCM known as OPA developed at the Laboratoire d'Océanographie Dynamique et de Climatologie [Marti et al., 1992; Delecluse et al., 1993; Madec and Imbard, 1996]. The horizontal grid spacing of the model varies between $0.5^{\circ}$ and $2^{\circ}$, with its higher meridional resolution in the equatorial regions providing a means to resolve better fine-scale features important in carbon cycle modeling [Aumont et al., 1999]. The model has 30 vertical levels, whose thickness varies from 10 $\mathrm{m}$ at the surface to $500 \mathrm{~m}$ at depth. Ten levels are located in the top $100 \mathrm{~m}$. The horizontal mesh is curvilinear and orthogonal. The grid is distorted in the Northern Hemisphere to shift the northern singularity over Asia [Madec and Imbard, 1996].

[9] Nonresolved subgrid-scale movements are parameterized by horizontal and vertical eddy diffusivities and viscosities. The horizontal eddy diffusivity coefficient is set everywhere to 2000 $\mathrm{m}^{2} \mathrm{~s}^{-1}$. The horizontal eddy viscosity coefficient equals $40 \times 10^{3}$ $\mathrm{m}^{2} \mathrm{~s}^{-1}$ within the whole ocean, except between $20^{\circ} \mathrm{S}$ and $20^{\circ} \mathrm{N}$ where it is reduced to reach $2000 \mathrm{~m}^{2} \mathrm{~s}^{-1}$ at the equator. Vertical eddy diffusivity and viscosity are not explicitly prescribed in the

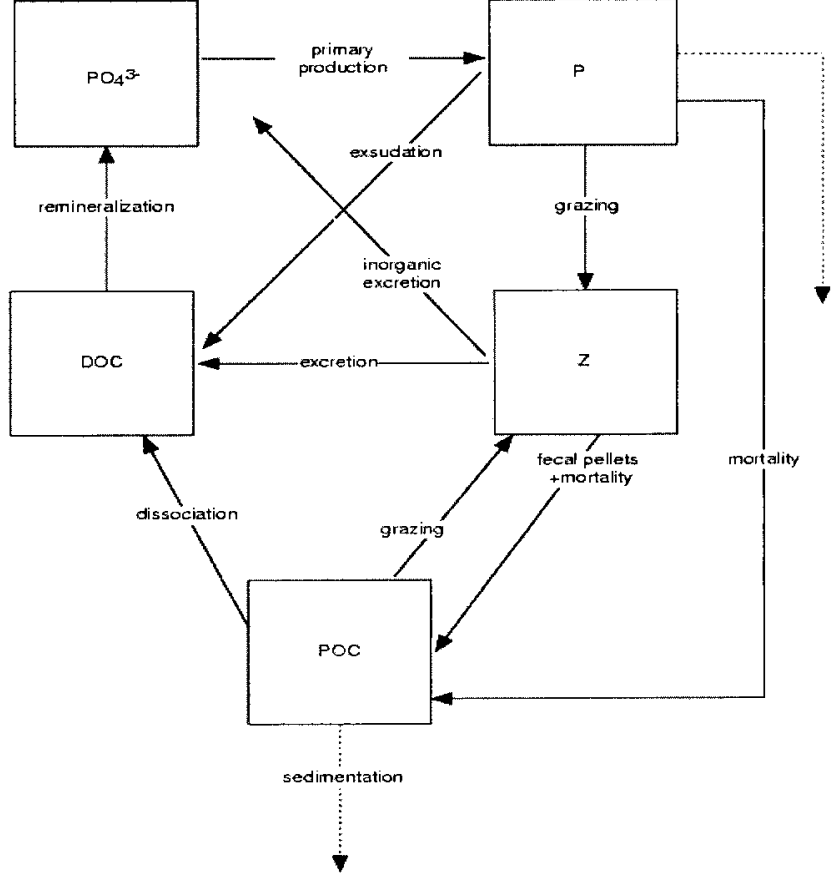

Figure 1. Schematic diagram of the processes represented in P3ZD.

model. These coefficients are computed from a prognostic model of the turbulence based on a 1.5 order closure scheme [Gaspar et al., 1990; Blanke and Delecluse, 1993]. Thus OPA predicts the strong vertical mixing within the mixed layer as well as the minimum of diffusion in the thermocline.

[10] The model is forced by monthly climatologies of wind stress [Hellermann and Rosenstein, 1983], heat fluxes, and water fluxes [Oberhüber, 1988]. Additionally, model temperatures and salinities are damped toward climatological values of Levitus [1982] with a restoring time constant of 12 days for both tracers. OPA is run in a semidiagnostic mode. In addition to the surface restoring, temperatures and salinities predicted by the model are also restored toward the climatological observations of Levitus [1982] throughout most of the ocean. The restoring time constant varies from 50 days just below the first level of OPA to 1 year in the deep ocean. Restoration is relaxed in four areas: (1) in the equatorial region between $10^{\circ} \mathrm{S}$ and $10^{\circ} \mathrm{N},(2)$ along the coasts, (3) in the high latitudes, and (4) in the mixed layer.

\subsection{Ocean Carbon Cycle Model}

[11] The biogeochemical model used here derives from the carbon cycle model P3ZD developed by Aumont [1998]. The production and export schemes of this model are based on five compartments: phosphate $\left(\mathrm{PO}_{4}^{3-}\right)$, phytoplankton $(P)$, zooplankton $(Z)$, particulate organic carbon (POC), and semilabile dissolved organic carbon (DOC). Figure 1 schematically shows the modeled interactions. All these variables, except phosphate, are expressed in terms of their carbon content. Additionally, this model also includes dissolved inorganic carbon, alkalinity, oxygen, and silicate. Phosphate instead of nitrate is used as the limiting nutrient to avoid the complexities of modeling the nitrate cycle. Photosynthesis is limited in the model to the upper $100 \mathrm{~m}$ of the ocean as a compromise between computing cost and the realities of biogeochemical cycling.

[12] The equations simulating the dynamics of the five reservoirs and a description of the interactions between these reservoirs are presented in Appendix A. Phytoplankton growth depends on the local conditions of light, temperature, and turbulence. In 
Table 1. Biological Parameter Values and Definitions

\begin{tabular}{|c|c|c|c|}
\hline Symbol & Unit & Value & Definition \\
\hline \multicolumn{4}{|c|}{ Phytoplankton } \\
\hline a & $d^{-1}$ & 0.6 & growth rate at $0^{\circ} \mathrm{C}$ \\
\hline $\mathrm{b}$ & & 1.066 & temperature sensitivity of growth \\
\hline $\mathrm{c}$ & ${ }^{\circ} \mathrm{C}^{-1}$ & 1 & temperature dependence of growth \\
\hline$\mu^{\max }$ & $\mathrm{d}^{-1}$ & & maximum phytoplankton growth rate \\
\hline$\alpha$ & $\mathrm{mmol} \mathrm{C}(\mathrm{mg} \mathrm{Chl})^{-1} \mathrm{~d}^{-1} \mathrm{~m}^{2} \mathrm{~W}^{-1}$ & 0.03 & initial slope of $P$ - $I$ curve \\
\hline$\beta$ & mmol C (mg Chl $)^{-1} \mathrm{~d}^{-1} \mathrm{~m}^{2} \mathrm{~W}^{-1}$ & 0.001 & photoinhibition parameter \\
\hline$\kappa_{r 0}$ & $\mathrm{~m}^{2}(\mathrm{~W} \mathrm{~d})^{-1}$ & 0.4 & extinction coefficient for red light \\
\hline$\kappa_{g 0}$ & $\mathrm{~m}^{2}(\mathrm{~W} \mathrm{~d})^{-1}$ & 0.03 & extinction coefficient for green light \\
\hline$\kappa_{c}$ & $\mathrm{~m}^{2}(\mathrm{~W} \mathrm{~d})^{-1}$ & 0.016 & phytoplankton self-shading parameter \\
\hline $\mathrm{I}_{0}$ & $\mathrm{~W} \mathrm{~m}^{-2}$ & & irradiance at the surface \\
\hline$\delta$ & & 0.05 & phytoplankton DOM exsudation fraction \\
\hline$K_{\mathrm{PO}_{4}}$ & $\mu \mathrm{mol}$ P L-1 & 0.03 & half-saturation constant for phosphate uptake \\
\hline$m_{P}$ & $\mathrm{~d}^{-1}$ & 0.05 & specific mortality rate \\
\hline$P_{0}$ & $\mu \mathrm{mol} \mathrm{C} \mathrm{L}{ }^{-1}$ & 1 & half-saturation constant for mortality \\
\hline $\mathrm{Chl}^{\max }$ & $\mathrm{mg} \mathrm{Chl}\left(\mathrm{mg} \mathrm{C}^{-1}\right.$ & $1 / 37$ & maximum $\mathrm{Ch} / / \mathrm{C}$ ratio \\
\hline$\frac{C h l^{\min }}{C^{\prime}}$ & mg Chl (mg C) ${ }^{-1}$ & $1 / 90$ & minimum $\mathrm{Ch} 1 / \mathrm{C}$ ratio \\
\hline $\begin{array}{l}c \\
I_{\mathrm{parm}}^{\max } \\
\end{array}$ & $\mathrm{W} \mathrm{m}^{-2}$ & 90 & critical irradiance for photoadaptation \\
\hline $\begin{array}{l}{ }^{1} \text { parm } \\
w_{P}\end{array}$ & $\mathrm{~m}^{3} \mu \mathrm{mol} \mathrm{C} \mathrm{C}^{-1} \mathrm{~d}^{-1}$ & 0.015 & aggregation coefficient \\
\hline \multicolumn{4}{|c|}{ Zooplankton } \\
\hline$\sigma$ & & 0.7 & grazing efficiency \\
\hline $\mathrm{g}$ & $\mathrm{d}^{-1}$ & 0.8 & maximum grazing rate \\
\hline$P_{1}$ & $\mu \mathrm{mol} \mathrm{C} \mathrm{L}{ }^{-1}$ & 6 & half-saturation constant for grazing \\
\hline$\gamma_{P}, \gamma_{\mathrm{POC}}$ & & $0.8,0.2$ & zooplankton feeding preferences \\
\hline$m_{Z}$ & $d^{-1}$ & 0.1 & specific mortality rate \\
\hline$r_{Z}$ & $d^{-1}$ & 0.05 & excretion rate \\
\hline$Z_{0}$ & $\mu \mathrm{mol} \mathrm{C} \mathrm{L}{ }^{-1}$ & 1 & half-saturation constant for mortality and excretion \\
\hline$\varepsilon$ & $\ldots$ & $0.3-0.95$ & fraction of zooplankton mortality exsuded as phosphate \\
\hline $\mathrm{p}_{P}$ & $\ldots$ & 0.8 & feeding preference of zooplankton for phytoplankton \\
\hline pPOC & $\cdots$ & 0.2 & feeding preference of zooplankton for POC \\
\hline \multicolumn{4}{|c|}{ Organic Matter } \\
\hline$\lambda_{\mathrm{DOC}}^{*}$ & $\mathrm{~d}^{-1}$ & 0.017 & DOC remineralization rate \\
\hline$K_{\mathrm{DOC}}^{1}$ & $\mu \mathrm{mol} \mathrm{P} \mathrm{L}{ }^{-1}$ & 0.3 & first half-saturation constant for DOC remineralization \\
\hline$K_{\mathrm{DOC}}^{2}$ & $\mu \mathrm{mol} \mathrm{C} \mathrm{L}-1$ & 15 & second half-saturation constant for DOC remineralization \\
\hline$\lambda_{\mathrm{POC}}$ & $d^{-1}$ & 0.05 & detrital breakdown rate \\
\hline $\begin{array}{l}\text { POOC } \\
\text { w }\end{array}$ & $\mathrm{m} \mathrm{d}^{-1}$ & 5 & detrital sinking speed \\
\hline \multicolumn{4}{|c|}{ Silica } \\
\hline$\frac{\mathrm{Si}}{\mathrm{T}}$ & & 0.47 & maximum $\mathrm{Si} / \mathrm{C}$ ratio \\
\hline $\begin{array}{ll}\mathrm{Simax}_{0} \\
\mathrm{Si}_{0}\end{array}$ & $\mu \mathrm{mol} \mathrm{Si} \mathrm{L}{ }^{-1}$ & 4 & half-saturation constant for variable $\mathrm{Si} / \mathrm{C}$ ratio \\
\hline $\mathrm{Si}_{0}$ & $\mu \mathrm{mol} \mathrm{Si} \mathrm{L}{ }^{-1}$ & 2 & half-saturation constant for silica uptake \\
\hline
\end{tabular}

addition to the direct effect of turbulence, which dilutes phytoplankton cells over the complete mixed layer, photosynthesis is limited for deep mixed layers following the formulation proposed by André [1990]. Furthermore the C/Chl ratio of phytoplanktonic cells is assumed to vary with the availability of light and nutrients on the basis of the relationship of Doney et al. [1996]. In the model, only one class of zooplankton is considered. Zooplankton is supposed to feed both on phytoplankton and on POC. The equation for grazing is adapted from the study by Fasham et al. [1990].

[13] The model includes two nonliving organic matter reservoirs: POC and DOC. In the top $100 \mathrm{~m}$ of the water column, POC is assumed to sink with a constant speed over the whole ocean. Once particles reach the bottom of the production zone, they are exported instantaneously into the intermediate and deep ocean with a prescribed profile [Martin et al., 1987]. POC breaks down to DOC according to simple first-order kinetics. DOC in the model is intended to represent the semilabile component of this compound, which was shown to be potentially important for vertical export of carbon [Murray et al., 1994]. Its modeled lifetime varies with the availability of nutrients and DOC between 2 months in surface equatorial waters and more than 5 years in the center of the oligotrophic subtropical gyres or in the thermocline.

[14] Finally, the model includes a simple parameterization of the silicon cycle. It computes the production of biogenic silicon from the production of particulate organic matter, the local temperature, and the availability of dissolved silicate. This process is particularly important to take into account when studying DMS because the different siliceous phytoplankton species (i.e., the diatoms) are known to be very poor producers of pDMSP and of DMS [Turner et al., 1995; Keller and Korjeff-Bellows, 1996].

\subsection{Initial Conditions and Model Integration}

[15] Biological parameters and their values are listed in Table 1. The model includes only one set of parameter values for the global ocean. As far as possible, values have been taken from the literature. However, three parameters, mortality coefficients, and the excretion rate of zooplankton have been adjusted within a "reasonable" range of values to achieve consistency with observations. This adjustment has been performed with 1-D models of the North Atlantic Bloom Experiment (NABE) and Bermuda Atlantic Time-series Study (BATS) stations, constructed from the OGCM.

[16] Phytoplankton and zooplankton concentrations were initialized to $1 \mu \mathrm{mol} \mathrm{CL}{ }^{-1}$ everywhere in the top $100 \mathrm{~m}$ of the model and to zero below. DOC concentrations were set to $1 \mu \mathrm{mol} \mathrm{CL}{ }^{-1}$ over the whole ocean. All other tracers were initialized with output from a previous simulation made by Aumont et al. [1999] without explicit planktons and DOC. The global circulation model uses a time step of 12 hours. Since biological processes are characterized 

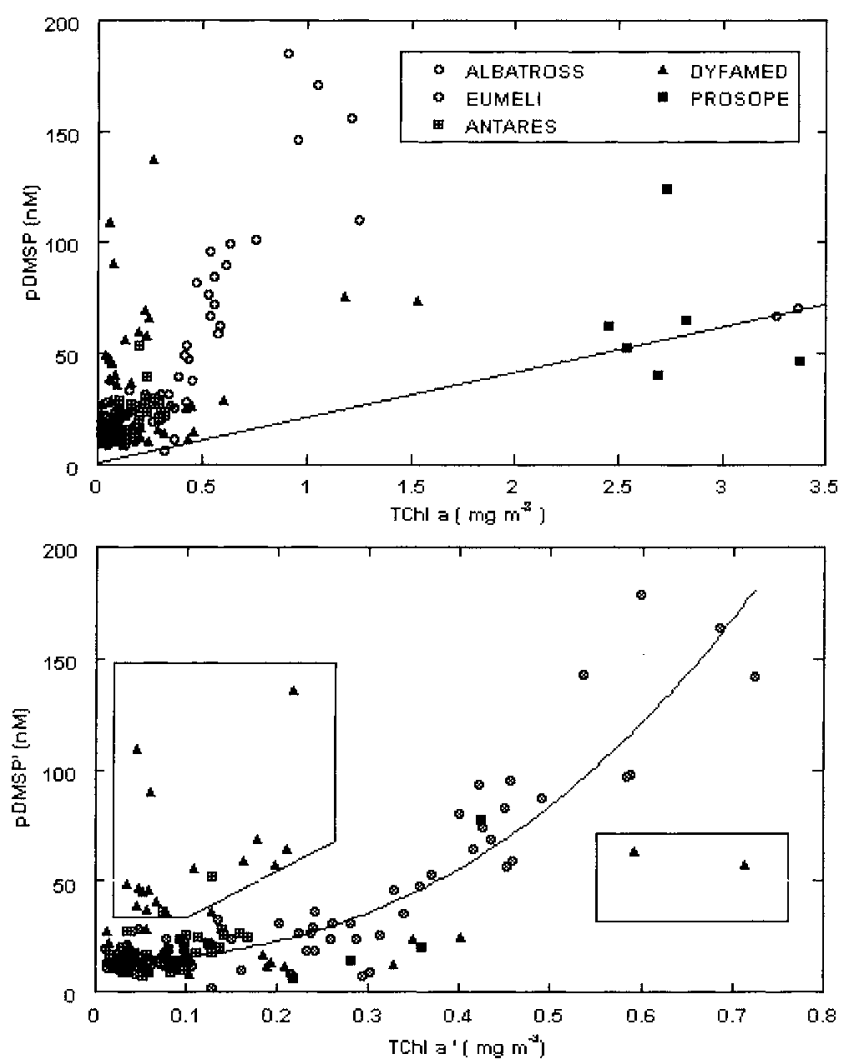

Figure 2. (a) Scatter diagram of pDMSP sea surface concentration (in $\mathrm{nM}$ ) plotted against TChl $a$ sea surface concentration (in $\mathrm{mg} \mathrm{Chl} \mathrm{m}{ }^{-3}$ ). Concentrations of both tracers were measured during the ALBATROSS, EUMELI, DYFAMED, PROSOPE, and Antares cruises. The lines denote the formulation we adopted for diatoms (see equation (1)). (b) Same as Figure 2a but for $\mathrm{pDMSP}^{\prime}$ and TChl $a^{\prime}$ (see text for definitions of pDMSP' and TChl $a^{\prime}$ ). The solid line shows the formulation we proposed to model seawater pDMSP concentrations associated with nondiatom species (see equation (4)). The 17 outliers correspond to samples collected in the Ligurian Sea during spring and summer of 1993 and 1994. They are not accounted for in the computation of the regression fit (see text for details).

by rather short time constants, in particular, the phytoplankton growth, we have divided this time step by four, thus using a 3 hour time step for the biological model. The export production is added over the four time steps and then distributed below the euphotic zone. Even with such a short time step, biological sources and sinks may produce negative concentrations. When this occurs, all the biological interactions involving the tracer are set to zero following the approach of Sarmiento et al. [1993]. To reach a quasi-equilibrium state, the model is integrated over the equivalent of 4000 years using the degredation-integration (DEGINT) technique [Aumont et al., 1998].

\section{Parameterization of pDMSP and DMS}

[17] The formulations we proposed to diagnose, pDMSP and DMS, derive from measurements made during the Antarctic Large Scale Box Analysis and the Role of the Scotia Sea (ALBATROSS), Eutrophe Mesotrophe Oligotrophe (EUMELI), Productivity of Pelagic Oceanic Systems (PROSOPE), Dynamique et Flux Atmosphériques en Méditerranée Occidentale/Mer Ligure (DYFAMED), and Antares cruises. They relate by nonlinear functions pDMSP and DMS concentrations to the chlor- ophyll content but also the trophic status of surface waters. Samples were collected in various areas of the Atlantic Ocean (ALBATROSS, EUMELI, and PROSOPE), of the Mediterranean Sea (PROSOPE and DYFAMED), and of the Indian sector of the Southern Ocean (ANTARES). The sites visited during these cruises have been investigated in detail for pigments, pDMSP, and DMS. Details concerning the sampling and analytical methods have been described in previously published studies: for EUMELI [Claustre, 1994; Claustre and Marty, 1995], ALBATROSS [Belviso et al., 2000], PROSOPE [Belviso et al., 2001] DYFAMED [Corn et al., 1996], and ANTARES [Blain et al., 2001; Cailliau et al., 1999].

\subsection{Diagnosis of pDMSP}

[18] The results of the different cruises show a significant relationship between pDMSP concentrations and TChl $a$ levels in sea surface waters in the range of $0.02-1.3 \mathrm{mg} \mathrm{Chl} \mathrm{m}^{-3}$ (Figure 2a). The outliers correspond to samples collected in upwelling areas of Western Africa during EUMELI 4 and PROSOPE, where TChl $a$ was greater than $2 \mathrm{mg} \mathrm{Chl} \mathrm{m}^{-3}$. In these samples, diatoms accounted for almost all of the standing stock of phytoplankton [Claustre, 1994; Belviso et al., 2001]. They exhibit low pDMSPto-TChl $a$ ratios around $20 \mathrm{mmol} \mathrm{g}{ }^{-1}$. Similarly, minimum values of this ratio, about $30 \mathrm{mmol} \mathrm{g}^{-1}$ are found north of Iceland during ALBATROSS where diatoms are dominant (about $60 \%$ of the whole standing stock of phytoplankton). A ratio of $20 \mathrm{mmol} \mathrm{g}^{-1}$ is thus suggested to be typical of phytoplankton communities dominated by microphytoplankton, i.e., diatoms and, to a lesser extent, dinoflagellates. This ratio is consistent with determinations performed in the Antarctic open surface waters (between 10 and 60 mmol $\mathrm{g}^{-1}$ [Turner et al., 1995]). It also agrees with the culture work of Keller and Korjeff-Bellows [1996] provided that a significant contribution of the dinoflagellates to the pDMSP-to-TChl $a$ ratio of the phytoplankton community is added (between 3 and $60 \mathrm{mmol} \mathrm{g}^{-1}$ ).

[19] To characterize the proportion of microphytoplankton within the whole phytoplnakton community, Claustre [1994] defined a trophic status ratio, the Fp ratio, as the ratio of the integrated concentrations of fucoxanthin and peridinin to the sum of the integrated concentrations of diagnostic pigments of all taxa that may be present in a plankton community [Claustre, 1994]. In our study, only surface concentrations are taken into account. As mentioned previously, the diatoms (and to a lesser extent, microphytoplankton) are distinct from the rest of the phytoplankton species in the sense that they produce much less pDMSP. Their contribution to the sea surface distribution of pDMSP was parameterized as follows:

$$
\operatorname{pDMSP}(\text { of diatoms })=20 \times \Gamma \mathrm{Chl} a \times \mathrm{Fp}
$$

[20] Equation (1) assumes that diatoms (plus dinoflagellates) account for Fp $\times$ TChl $a$ of the total concentration of Chl $a$. This assumption implies that the ratio of TChl $a$ to the sum of all diagnostic pigments is constant at the sea surface. Using various data measured in the Atlantic Ocean and in the Mediterranean Sea, Claustre [1994] has found a very significant linear correlation $(R=0.96$ [see Claustre, 1994, Figure 1]) between TChl $a$ and the sum of all diagnostic pigments, with a slope equal to 0.7. These data support our assumption of a constant ratio.

[21] The contribution of the remaining phytoplankton community to pDMSP and TChl $a$ was parameterized as follows:

$\mathrm{pDMSP}($ of non diatoms $)=\mathrm{pDMSP}^{\prime}=\mathrm{pDMSP}$

$$
-(20 \times \Gamma \mathrm{Chl} a \times \mathrm{Fp})
$$

TChl $a$ (of non diatoms $)=\operatorname{TChl} a^{\prime}=\mathrm{TChl} a \times(1-\mathrm{Fp})$ 


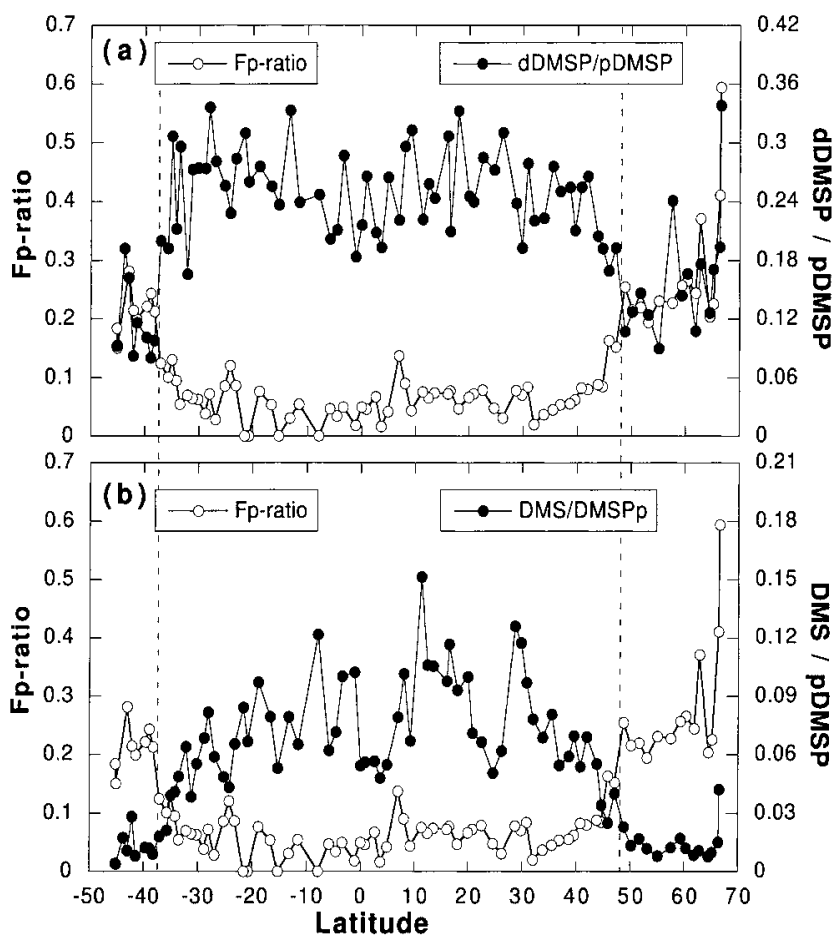

Figure 3. Latitudinal variations (a) of the surface dDMSP-topDMSP and Fp ratios and (b) of the surface DMS-to-pDMSP and Fp ratios measured during the ALBATROSS expedition. Dots indicate the sampling positions. The dashed vertical lines indicate the latitudes where the ratios undergo abrupt changes.

[22] A scatterplot of surface $\mathrm{pDMSP}^{\prime}$ versus surface TChl $a^{\prime}$ concentrations shows that the data sets are generally highly consistent (Figure 2b). In particular, the outliers corresponding to the eutrophic sites of the EUMELI and PROSOPE cruises (Figure 2a) fall within the range given by the other data when TChl $a$ and pDMSP concentrations are corrected for the contribution of diatoms. Samples collected at the DYFAMED site in the Ligurian Sea during spring and summer of 1993 and 1994 suggest specific characteristics at this station. The pDMSP concentrations are surprisingly higher than at any other site. A detailed analysis of pigment concentrations shows that DMSP production or accumulation by microheterotrophs is rather important at this station, increasing pDMSP concentrations by about $15 \mathrm{nM}$ [Belviso et al., 2001].

[23] We note that the relationship between $\mathrm{pDMSP}^{\prime}$ and TChl $a^{\prime}$ in the range $0.02-0.8 \mathrm{mgChl} \mathrm{m}{ }^{-3}$ is not linear. The following function best accounts for the nonlinearity when samples collected

Table 2. Fp,pDMSP-to-Chl $a$, and DMS-to-pDMSP Ratios Measured Along the EUMELI Expeditions in the Subtropical Atlantic Ocean

\begin{tabular}{lccc}
\hline EUMELI Sites & $\begin{array}{c}\text { Fp Ratio, } \\
\mathrm{mmol} \mathrm{g}^{-1}\end{array}$ & $\begin{array}{c}\text { pDMSP/Chl a, } \\
\mathrm{mmol} \mathrm{g}^{-1}\end{array}$ & $\begin{array}{c}\text { DMS/pDMSP, } \\
\mathrm{mmol} \mathrm{g}^{-1}\end{array}$ \\
\hline Oligotrophic & $0.09 \pm 0.02(n=4)$ & $504 \pm 158(n=6)$ & $0.08 \pm 0.01(n=6)$ \\
Mesotrophic & $0.24 \pm 0.12(n=4)$ & $153 \pm 39(n=4)$ & $0.03 \pm 0.01(n=4)$ \\
Eutrophic $^{\mathrm{a}}$ & $0.53 / 0.55$ & $88 / 129$ & $0.02 / 0.02$ \\
Eutrophic $^{\mathrm{b}}$ & 0.91 & 21 & $\ldots$ \\
\hline
\end{tabular}

\footnotetext{
${ }^{\mathrm{a}}$ Only two measurements were performed at this station.

${ }^{\mathrm{b}}$ Eutrophic waters with Chl $a$ concentration of $3.3 \mathrm{mg} \mathrm{Chl} \mathrm{m}^{-3}$; no DMS measurements are available.
}

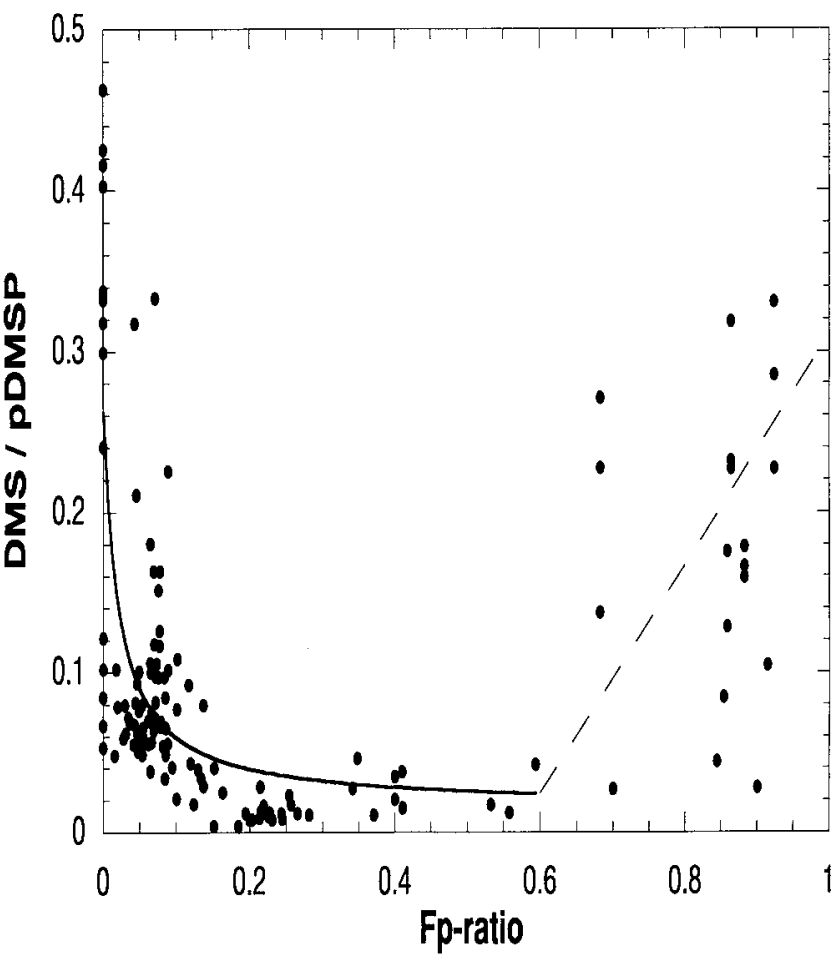

Figure 4. Scatter diagram of the sea surface DMS-to-pDMSP ratio plotted against the sea surface Fp ratio. Both quantities were measured during the ALBATROSS, EUMELI, DYFAMED, PROSOPE, and Antares cruises. The solid and dashed lines illustrate the formulation that is adopted in the model to simulate the DMS-to-pDMSP ratio.

at DYFAMED during spring and summer 1993 and 1994 are not accounted for:

$\mathrm{pDMSP}^{\prime}=13.64+\frac{0.10769}{\left(1 .+24.97 \mathrm{TChl} a^{\prime}\right)^{-2.5}}, n=189, R^{2}=0.84$

[24] The $\chi^{2}$ of this fit equals 22.4 , indicating a good significance for the chosen parameterization. In this relationship the value of the intercept at the origin is significantly higher than zero (13.64 $\mathrm{nM}$ ). This supports observations showing enhanced pDMSP production in very oligotrophic areas [Andreae, 1986; Keller and Korjeff-Bellows, 1996] or accumulation of DMSP by heterotrophic organisms [Wolfe, 1996]. Thus, using both equations (1) and (4), the diagnosis of pDMSP from TChl $a$ modulated by the Fp ratio is as follows:

$$
\begin{aligned}
\mathrm{pDMSP}= & (20 \times \mathrm{TChl} a \times \mathrm{Fp}) \\
& +\left(13.64+\frac{0.10769}{[1 .+24.97(1-\mathrm{Fp}) \times \mathrm{TChl} a]^{-2.5}}\right)
\end{aligned}
$$

\subsection{Diagnosis of DMS}

[25] Part of the DMS data set used in this study is a subset of a high-resolution transect with 930 DMS determinations collected during ALBATROSS [Belviso et al., 2000]. Contrary to pDMSP, there was a significant enhancement of DMS in tropical and equatorial waters (Figure 5). The meridional distributions of the Fp, dDMSP-to-pDMSP, and DMS-to-pDMSP ratios are shown on Figures $3 \mathrm{a}$ and $3 \mathrm{~b}$. Both the dDMSP-to-pDMSP and DMS-topDMSP ratios decrease poleward except at $66^{\circ} \mathrm{N}$ off Iceland where 
a local abrupt increase was observed. However, the DMS-topDMSP ratio shows a more steady decreasing trend poleward than the dDMSP-to-pDMSP ratio, which undergoes abrupt changes around $48^{\circ} \mathrm{N}$ and $38^{\circ} \mathrm{S}$ denoted by the vertical lines in Figure 3. The Fp ratio also shows discontinuities coinciding remarkably with the previous ones. Fp ratios ranged from 0 to $60 \%$. North of $65^{\circ} \mathrm{N}$, the $\mathrm{Fp}$ and the previous two ratios followed the same trend. However, elsewhere, the broad trends are clearly opposite, areas with high (low) Fp ratios showing low (high) DMS-to-pDMSP and dDMSP-to-pDMSP ratios.

[26] These results confirm previous observations carried out in the tropical Atlantic Ocean during EUMELI cruises (Table 2). A sixfold increase of the $\mathrm{Fp}$ ratio between site 0 and site $\mathrm{E}$ corresponding to a fourfold to eight-fold decrease of the DMSto-pDMSP ratio was observed. Available data from PROSOPE, DYFAMED, and ANTARES also suggest this behavior with higher DMS-to-pDMSP ratios for low Fp ratios (see Figure 4).

[27] The DMS-to-pDMSP ratios from the different cruises (ALBATROSS, EUMELI, PROSOPE, DYFAMED, and ANTARES) are plotted against the Fp ratios in Figure 4. These independent sets of ratios are significantly correlated $\left(R^{2}=0.51\right.$ and $n=125$ ), the best fit relationship being

$$
\text { DMS }- \text { to }- \text { pDMSP ratio }=0.015316+\frac{0.005294}{0.0205+\mathrm{Fp}}
$$

The $\chi^{2}$ of this fit equals 47.4 , suggesting a reasonable significance for the chosen parameterization.

[28] Figure 4 also shows results of a survey of Fp and DMS-topDMSP ratios carried out in a fjord of northern Norway (Balsfjord) where a diatom bloom took place in April 1996. These data (J. Stefels, unpublished data, 1999) document the area of Fp ratios higher than 0.6. Unfortunately, no clear relationship between Fp ratios and DMS-to-pDMSP ratios seems to exist according to these points. They only tend to suggest higher DMS-to-pDMSP ratios than intermediate Fp ratios. For Fp ratios around 0.89, the mean DMS-to-pDMSP ratio was $0.23 \pm 0.07(n=14)$. To complete our relationship for Fp ratios higher than 0.6 , we arbitrarily decided to use a linear function defined as follows:

$$
\mathrm{DMS}-\text { to }-\mathrm{pDMSP}-\text { ratio }=0.674 \mathrm{Fp}-0.371, \quad \mathrm{Fp}>0.6
$$

[29] Coefficients of equation (7) have been determined so that the line crosses the curve defined by equation (6) when the Fp ratio equals 0.6 and so that the computed DMS-to-pDMSP ratio equals 0.23 when the Fp ratio is 0.89 . Despite the fact that this relationship is only a very poor description of the observed DMS-to-pDMSP ratios the total area of the ocean showing $\mathrm{Fp}$ ratios higher than 0.6 encompasses $<5 \%$ of the global ocean according to the model.

[30] Finally, from equations (5), (6), and (7), DMS can be deduced only from a trophic status ratio $(\mathrm{Fp})$ and the chlorophyll concentrations (TChl $a$ ) of sea surface waters. These relationships are strongly nonlinear, as expected from previous studies that have shown that both pDMSP and DMS concentrations cannot be linearly related to parameters like chlorophyll, temperature, or nutrients [Kettle et al., 1999]. We should also note that pDMSP is not necessary to compute DMS concentrations. However, this tracer can be used as a diagnostic of the robustness of our parameterization by comparing the predicted distribution to available observations.

\section{Model Results Along the ALBATROSS Transect}

[31] The relationships presented in section 3 (equations (5) and (6)) are used in the model to simulate surface DMS and pDMSP concentrations. These relationships have been derived from measurements made for a large part during the ALBATROSS cruise. Thus, rather than a validation, these observations may be used to test the ability of the model to reproduce realistic distributions of the necessary input parameters, i.e., TChl $a$ and the $\mathrm{Fp}$ ratio. Furthermore, they represent a means to validate the robustness of the formulations we proposed. In this section all the data obtained during the ALBATROSS cruise have been interpolated onto the model grid to ensure a robust comparison with the model results.

[32] The Fp ratio is the first needed parameter. However, as the model does not include any explicit speciation of phytoplankton, this ratio is not directly predicted. As a proxy, we introduce the silica ratio, which we define as the ratio of the local simulated production of biogenic silica to the maximum production of biogenic silica (see also Appendix A):

$$
\text { Silica ratio }=\frac{P B \mathrm{Si}}{P_{\max } B \mathrm{Si}}=f(T) \frac{\mathrm{Si}}{\mathrm{Si}+\mathrm{Si}_{0}} \frac{\mathrm{Si}}{\mathrm{Si}+\mathrm{Si}_{1}}
$$

[33] This ratio is then a function of the temperature $T$ and of the local silica concentration Si. Bounded by 0 and 1 , it characterizes the relative intensity of the particulate export of biogenic silica. This ratio increases with the abundance of diatoms, and thus of microphytoplankton, as does the Fp ratio.

[34] First, to test whether this silica ratio is a proxy of the Fp ratio, we compared both ratios along the ALBATROSS cruise (Figure 5a). The predicted silica ratio reproduces quite well the observed latitudinal variations of the $\mathrm{Fp}$ ratio. As expected, the low latitudes, which correspond mostly to oligotrophic regions, exhibit very low values, typically below 0.05 . On the other hand, higher values are found in the middle and high latitudes, where this ratio may exceed 0.3 . These regions present the higher levels of nutrients necessary for the development of microphytoplankton. However, in the Southern Ocean, south of $35^{\circ} \mathrm{S}$, the modeled silica ratio is about twice as high as the Fp ratio. This discrepancy originates from the representation in IPSL-OCCM2 of the silica front off the Argentina plateau, which is about $10^{\circ}$ too far to the north. This reasonable agreement between the latitudinal variations of both ratios, at least for the available observations, supports our hypothesis that the silica ratio may be considered as a proxy of the Fp ratio. Thus the silica ratio is substituted into the Fp ratio in equations (5) and (6) to diagnose pDMSP and DMS in the model.

[35] Second, we compared the simulated distribution of TChl $a$ to the observations (Figure 5b). Both present the same main features. Maximum concentrations of TChl $a$ are found in the high latitudes where nutrients are not limiting the phytoplankton growth. The model tends to underestimate the levels of chlorophyll observed north of $45^{\circ} \mathrm{N}$. In the subtropical gyres the lack of nutrients inhibits the development of phytoplankton, resulting in very low chlorophyll concentrations both in the model and in the observations. In the equatorial regions the fields seen in the observations are not well simulated by the model. The model predicts values that are too high at the equator and underestimates chlorophyll at $10^{\circ} \mathrm{N}$ in the North Equatorial Current (NEC). However, POLDER observations for the ADEOS platform show a band of chlorophyll about $2^{\circ}$ wide at the equator with concentrations in the range $0.2-0.4 \mathrm{mg} \mathrm{Chl} \mathrm{m}^{-3}$ (C. Moulin, personal communication, 1999). In the NEC a modeling study has shown that the biological production is significantly enhanced by the eddy activity [Dadou et al., 1996]. Since the model does not resolve the eddies, this may explain why the predicted chlorophyll levels are too low in this area. Furthermore, in this zone of the NEC chlorophyll concentrations are also enhanced by advection of coastal waters enriched in nutrients originating from the Guinea Dome [Belviso et al., 2000]. This particular feature may be simulated incorrectly by the model because its resolution is too coarse. 
a)

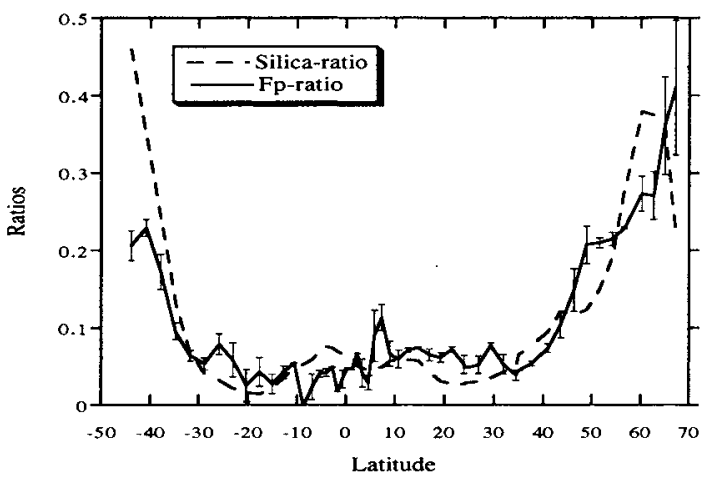

c)

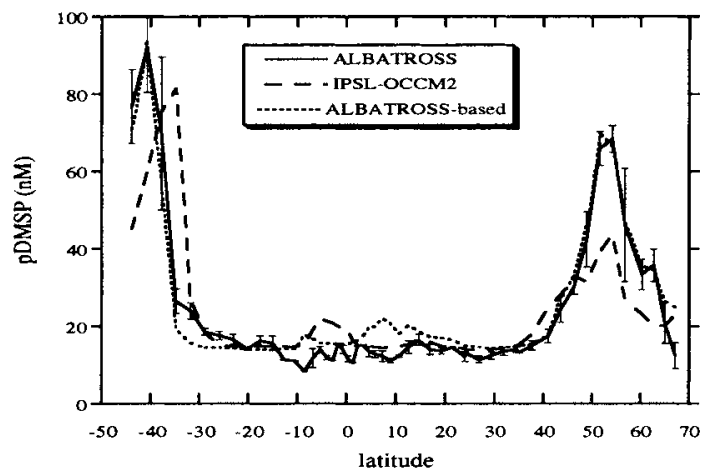

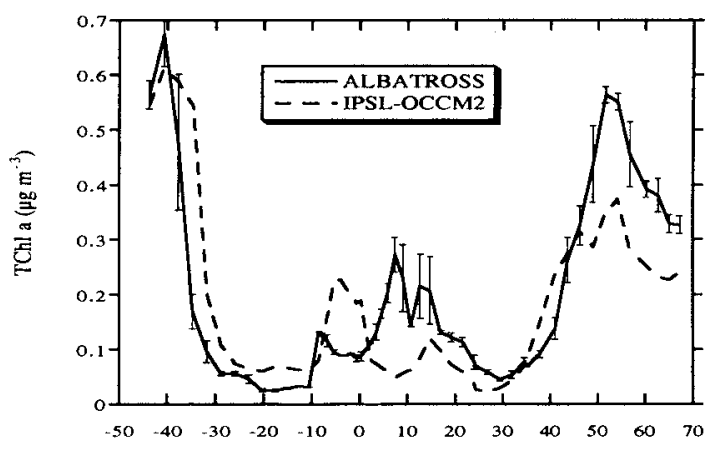

d)

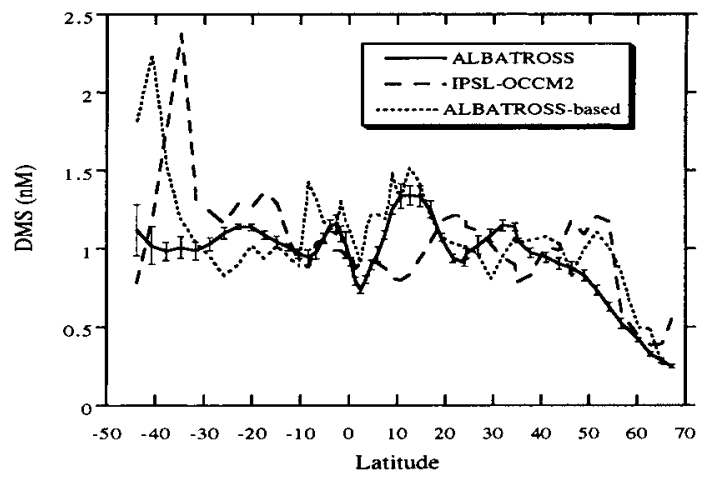

Figure 5. Latitudinal variations along the ALBATROSS transect of (a) the observed Fp ratio (solid line) and the simulated silica ratio (dashed line), (b) surface chlorophyll concentrations (in $\mathrm{mg} \mathrm{Chl} \mathrm{m}^{-3}$ ), (c) sea surface pDMSP concentrations (in $\mathrm{nM}$ ), and (d) sea surface DMS concentrations (in $\mathrm{nM}$ ). In Figures $5 \mathrm{~b}$, 5c, and $5 \mathrm{~d}$ the solid line shows the observations; the dashed line represents the simulated values; and the dotted line displays concentrations computed from observed chlorophyll concentrations and Fp ratios. All data obtained during the ALBATROSS cruise are interpolated onto the model grid. The error bars depict the standard deviation of the data in the interpolation process. A five-point running mean has been applied to DMS concentrations to remove strong mesoscale variations that cannot be resolved by the model (see Belviso et al. [2001]).

[36] Third, simulated and observed pDMSP concentrations are displayed on Figure 5c. Two features characterize the latitudinal variations of pDMSP, both in the model and in the observations. First, the high latitudes exhibit very high pDMSP concentrations, associated with the high chlorophyll levels. Consequently, as for chlorophyll, the model underestimates the pDMSP concentrations north of $45^{\circ} \mathrm{N}$. Second, low and relatively uniform pDMSP concentrations are found in the middle and low latitudes, with values around $15 \mathrm{nM}$. The model predicts a small peak of pDMSP just south of the equator, which results from the simulated chlorophyll concentrations, which are too high.

[37] Fourth, Figure 5d shows the observed and simulated DMS concentrations along the ALBATROSS cruise in OctoberNovember. The model captures the correct order of magnitude of the observed DMS concentrations. In particular, despite their comparatively much stronger biological activity it predicts lower values in the high latitudes, especially in the Northern Hemisphere, than in the low latitudes. However, the model is not able to simulate very well the observed regional variations of DMS. In particular, it overpredicts the observations between $40^{\circ}$ and $55^{\circ} \mathrm{N}$. This discrepancy is caused (1) by overestimated pDMSP concentrations resulting from too large simulated $\mathrm{Chl} a$ concentrations between $35^{\circ}$ and $45^{\circ} \mathrm{N}$ and (2) by an underestimated silica ratio between $45^{\circ}$ and $55^{\circ} \mathrm{N}$, which produces a too high DMS-toDMSP ratio. Furthermore, the model fails to simulate the maximum DMS concentrations observed around $10^{\circ} \mathrm{N}$ in the NEC. Yet, the predicted silica ratio and $\mathrm{pDMSP}$ concentrations agree reasonably well with the observations. In fact, in this area the observed DMS-to-DMSP ratios lie within 0.1 and 0.15 (see Figure 3), about twice as high as the ratio computed from equation (5) with the observed $\mathrm{Fp}$ ratio (about 0.07 ). This problem illustrates the limitations of the relationships we derived from the observations.

[38] Results displayed on Figures $5 \mathrm{c}$ and $5 \mathrm{~d}$ show that the model generally reproduces better pDMSP than DMS latitudinal variations. However, inferring whether discrepancies are related to the formulations we derived from the data or to incorrectly simulated chlorophyll concentrations and silica ratio in IPSL-OCCM2 is not straightforward. To assess better the robustness of the proposed parameterizations of both pDMSP and DMS, Figures $5 \mathrm{c}$ and $5 \mathrm{~d}$ also present pDMSP and DMS concentrations computed from the observed chlorophyll concentrations and $\mathrm{Fp}$ ratios. The computed pDMSP distribution is in very close agreement with the observations, except between the equator and $15^{\circ} \mathrm{N}$, where computed values are about twice as high as the measurements. Chlorophyll 
a)
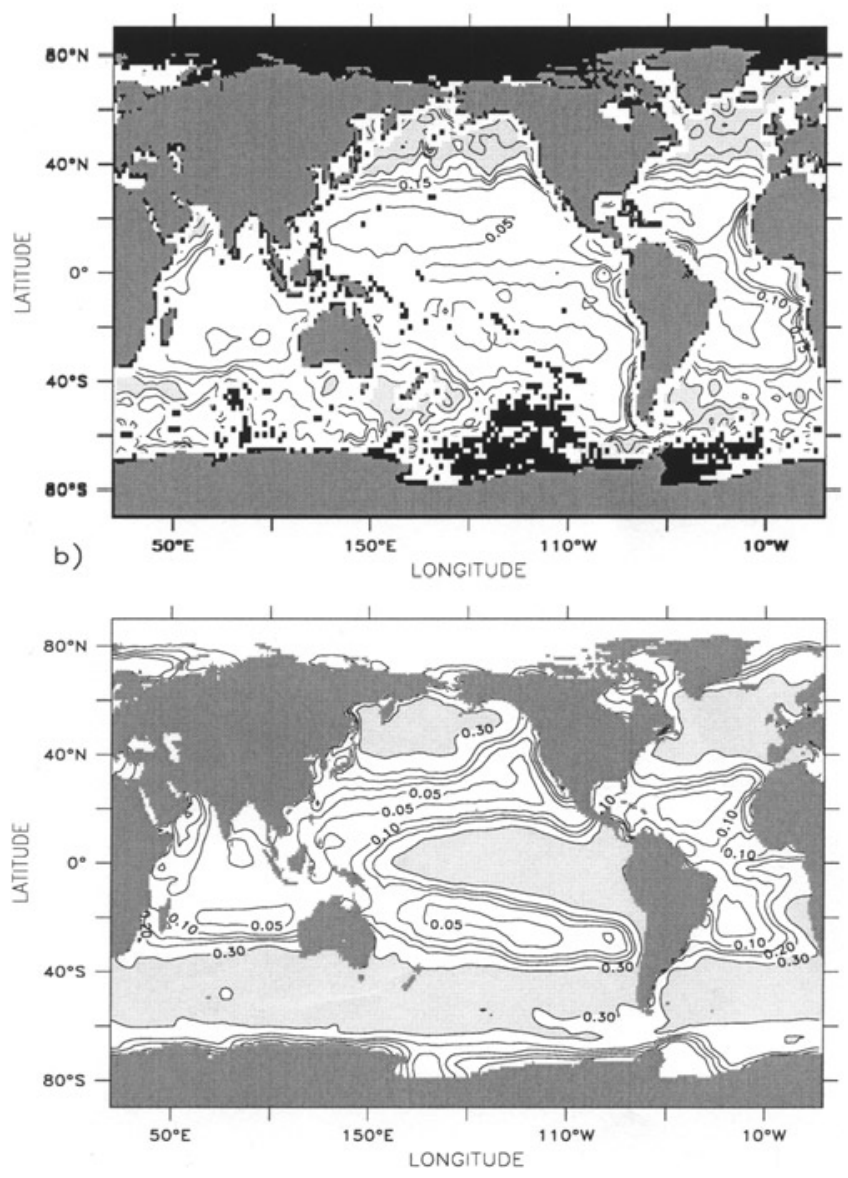

Figure 6. Annual mean distribution of surface chlorophyll (in mg

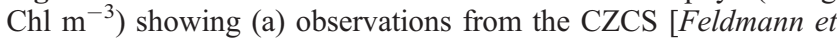
al., 1989] and (b) results of IPSL-OCCM2. Isoline spacings are 0.05 between 0 and $0.2,0.1$ between 0.2 and $0.3,0.5$ between 0.5 and 2, and 1 between 2 and 5. Observations are interpolated onto the model grid. Dark areas in the observations are regions where no data are available.

concentrations in this area range from 0.15 and $0.25 \mathrm{mg} \mathrm{Chl} \mathrm{m}^{-3}$. These values correspond to the dots that are well below the curve fit of Figure 2b.

[39] Concerning DMS, the agreement is much better than the distribution predicted by the OCCM model. In particular, DMS concentrations between $35^{\circ}$ and $60^{\circ} \mathrm{N}$, despite still being slightly too high, are much lower than what IPSL-OCCM 2 predicts. Furthermore, latitudinal variations in the low latitudes are more realistic, with a peak around $10^{\circ} \mathrm{N}$ and a second maximum just south of the equator. However, the peak around $10^{\circ} \mathrm{N}$ is a result of the computed concentrations of pDMSP being too high, whereas in the data, this peak results from higher DMS-topDMSP ratios that are not correctly resolved by equation (6). Computed values in the southern part of the transect (south of $35^{\circ} \mathrm{S}$ ) are much too high. They reach almost $2.5 \mathrm{nM}$, whereas in the observations they remain relatively constant close to $1 \mathrm{nM}$. In fact, the Fp ratios in this domain are around $0.1-0.25$. The observed DMS-to-pDMSP values in this range of the Fp ratio are generally much lower than those computed from equation (6), especially for Fp ratios between 0.15 and 0.25 (see Figure 4). However, despite this problem both pDMSP and DMS concentrations computed from observed chlorophyll concentrations and Fp ratios show a rather good agreement with the observations.
This puts some confidence in the relationships we proposed to diagnose pDMSP and DMS distributions.

\section{Chlorophyll Distributions}

[40] Equations (5) and (6) are used to compute pDMSP and DMS surface concentrations only from surface chlorophyll concentrations and the Fp ratio predicted by the OCCM. Thus a necessary condition to achieve a realistic distribution of surface DMS and pDMSP is to simulate a realistic distribution of surface chlorophyll. In this section we present predicted Chl $a$ concentrations, which we compare both to in situ data and to global satellite-derived fields.

\subsection{Global Distribution}

[41] Data obtained from satellite imagery by the Coastal Zone Color Scanner [Feldmann et al., 1989] offer the means to validate the surface distribution of chlorophyll as predicted by the model. As these data consist of about 8 years of observations, they could be averaged to give climatological mean fields directly comparable to model output. Unfortunately, such a validation is not yet feasible for the other modeled components of organic matter, i.e., zooplankton, POC, and DOC. Figure 6 shows the annual mean climatological satellite-derived and modeled distributions of chlorophyll at the surface. The satellite gives average values for the upper $10-20 \mathrm{~m}$ of the ocean, thus directly comparable to the model output. The main observed patterns are reproduced by the model. Very low concentrations of chlorophyll are found in the oligotrophic subtropical gyres. They drop below $0.05 \mathrm{mg} \mathrm{Chl} \mathrm{m}^{-3}$ both in the model and in the observations. In the equatorial Pacific Ocean the predicted chlorophyll concentrations are largely overestimated. Observations show concentrations of about $0.1-0.2 \mathrm{mg} \mathrm{Chl} \mathrm{m}^{-3}$, while in the model they exceed $0.4 \mathrm{mg} \mathrm{Chl} \mathrm{m}^{-3}$. A recent in situ experiment has shown that the addition of iron in this region induces a strong phytoplankton bloom, demonstrating that biological activity is iron-limited there [Coale et al., 1996]. Another study suggests that phytoplankton growth may also be controlled by the availability of silicate in the equatorial Pacific Ocean [Dugdale and Wilkerson, 1998]. As the model includes none of these nutrient limitations, this may explain these overestimated chlorophyll values.

[42] In the high latitudes of the Northern Hemisphere, annual mean concentrations of chlorophyll are high, both in the satellitederived data and in the model. North of $45^{\circ} \mathrm{N}$, the model predicts values that are too low in the Atlantic and Pacific Oceans. Observations show chlorophyll concentrations that may exceed 2 $\mathrm{mg} \mathrm{Chl} \mathrm{m} \mathrm{m}^{-3}$, whereas in the model these concentrations always

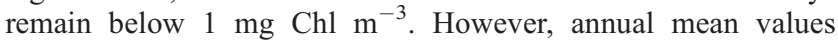
obtained from satellite data at those latitudes are questionable. Because of low incident irradiance, the satellites tend to overestimate the chlorophyll concentrations from late fall until early spring [Yoder et al., 1993].

[43] In the Southern Ocean the model simulates a rather homogeneous distribution of chlorophyll, both latitudinally and longitudinally. On the other hand, the observations reveal large spatial variability. Many lower chlorophyll concentrations are found in the eastern parts of the ocean basins, especially in the Pacific sector of the Southern Ocean. In situ measurements suggest that this variability may be due to the limitation by nutrients other than phosphate or nitrate, i.e., iron [Martin and Fitzwater, 1988; de Baar et al., 1995] or silicate [Jacques, 1983; Sommer, 1986]. In particular, eastern parts of the ocean basins are regions far away from any potential upstream or upwind source of iron. Furthermore, satellite data may introduce additional uncertainties. By comparing these data with in situ observations, Sullivan et al. [1993] has shown that the satellite data may underestimate by $45 \%$ the observed chlorophyll concentrations in the Southern Ocean during the austral spring and summer (from October to March). 
a)
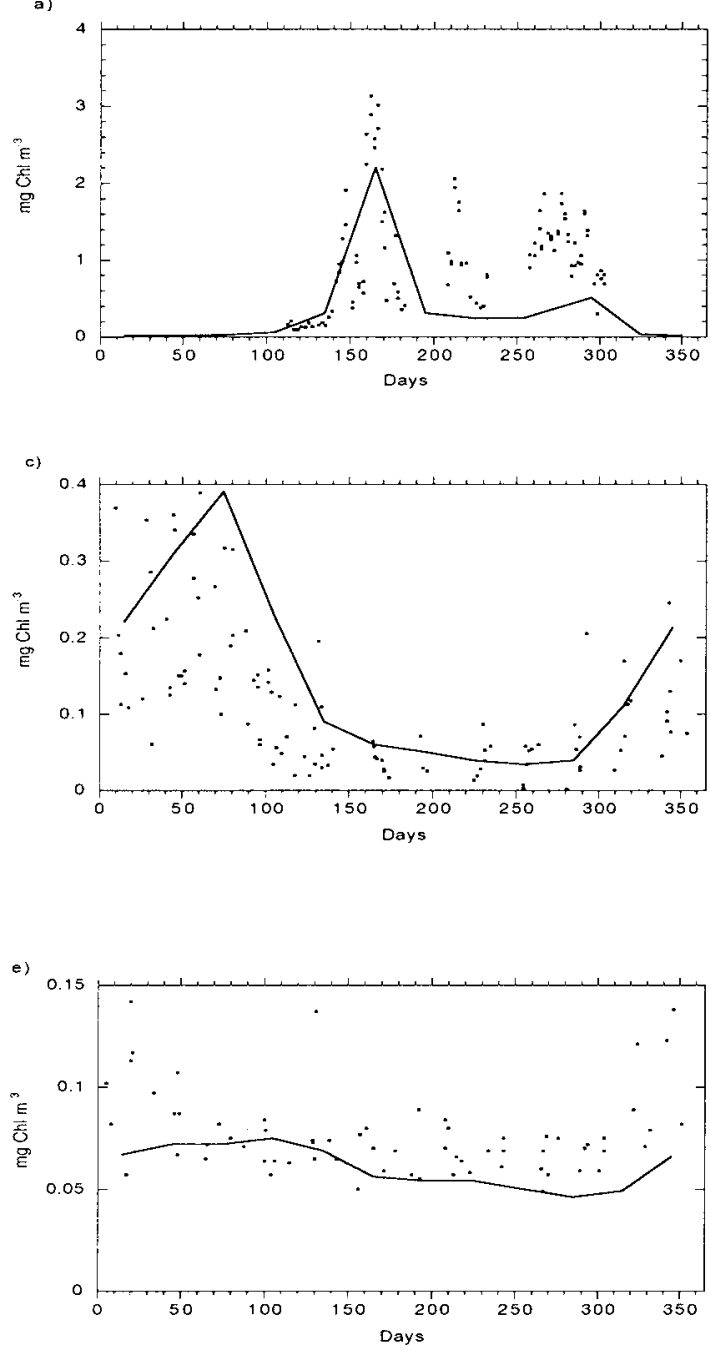
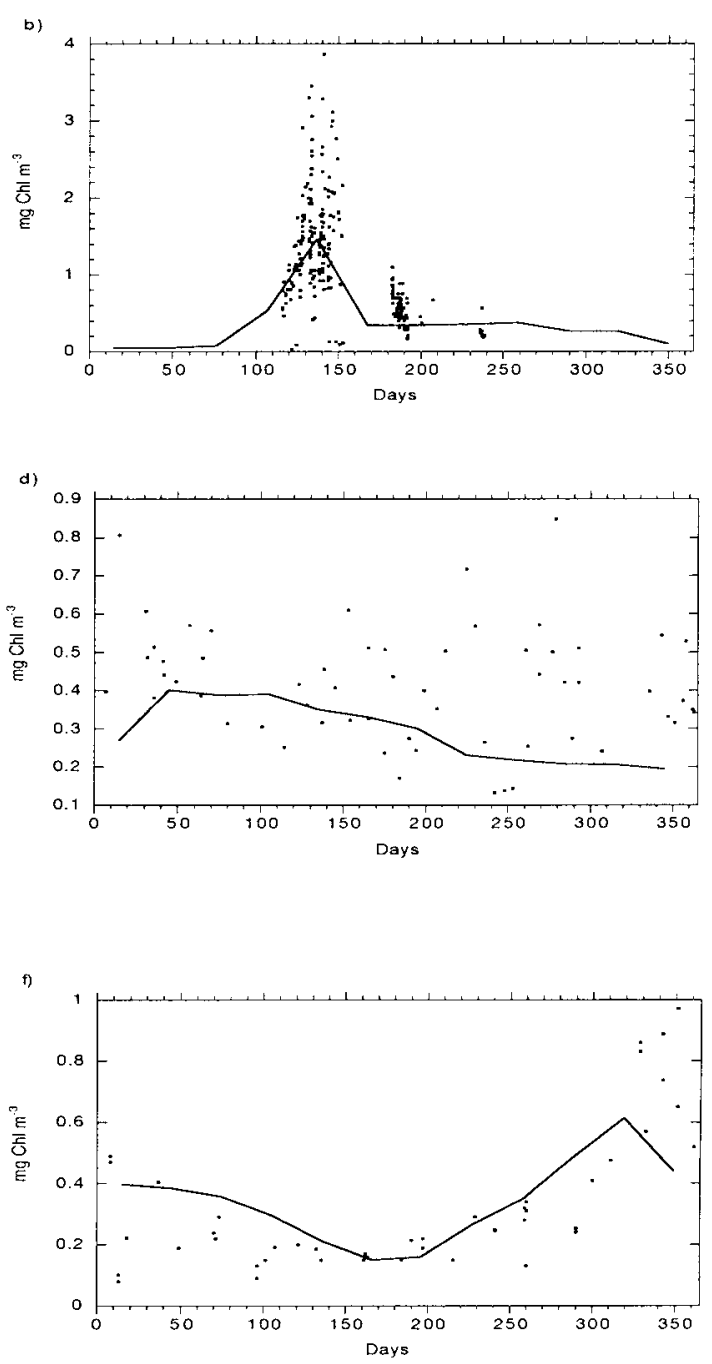

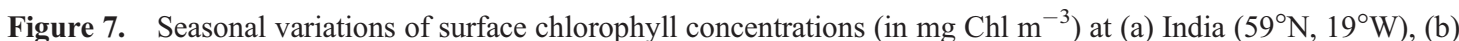
NABE $\left(47^{\circ} \mathrm{N}, 18^{\circ} \mathrm{W}\right)$, (c) BATS $\left(31^{\circ} \mathrm{N}, 64^{\circ} \mathrm{W}\right)$, (d) Station $\mathrm{P}\left(50^{\circ} \mathrm{N}, 145^{\circ} \mathrm{W}\right)$, (e) HOT $\left(22^{\circ} \mathrm{N}, 158^{\circ} \mathrm{W}\right)$, and (f) KERFIX $\left(50^{\circ} \mathrm{S}, 68^{\circ} \mathrm{E}\right)$. Dots denote the observations; solid line indicates model results.

[44] Despite its coarse resolution the model is able to simulate most of the elevated concentrations of chlorophyll observed in the shelf areas. In particular, there are clear maximums of chlorophyll along the Californian coast and off the Guinean coast, as observed.

\subsection{Seasonal Variability}

[45] To study the ability of the model to reproduce the seasonal variability of phytoplankton, simulated chlorophyll concentrations were compared to observations at different stations located in the North Atlantic Ocean (India, NABE, and BATS), in the North Pacific Ocean (Station Papa (Station P), Hawaii Ocean Time-series Program (HOT)) and in the Southern Ocean (KERFIX) (Figure 7). We chose this approach rather than a global comparison to satellite data because, as we already mentioned, winter values observed by the satellite may be questionable in the high latitudes.

[46] The high latitudes of the North Atlantic Ocea are characterized by the occurrence of strong phytoplankton blooms during spring. Then, the exhaustion of nutrients and the increasing grazing pressure by zooplankton lead to a significant decrease of the phytoplankton concentrations. At the NABE station $\left(47^{\circ} \mathrm{N}\right.$, $18^{\circ} \mathrm{W}$ ) the model is in fairly good agreement with the observations. The phytoplankton bloom occurs in May, during which simulated concentrations reach $1.4 \mathrm{mg} \mathrm{Chl} \mathrm{m}^{-3}$. In June, chlorophyll values decline to about $0.5 \mathrm{mg} \mathrm{Chl} \mathrm{m}^{-3}$. Data are lacking to infer whether there is a second bloom during fall when the deepening of the mixed layer supplies nutrients at the surface. The model does not simulate such a bloom. Farther north, at station India $\left(59^{\circ} \mathrm{N}\right.$, $19^{\circ} \mathrm{W}$ ), the spring bloom starts on average about 1 month later than at NABE. This bloom seems also to be more intense both in the observations and in the model. Data show the succession of two secondary blooms in July and in September with chlorophyll concentrations that exceed $1 \mathrm{mg} \mathrm{Chl} \mathrm{m}{ }^{-3}$. The model simulates only one secondary bloom, which is strongly underestimated.

[47] At station BATS $\left(31^{\circ} \mathrm{N}, 64^{\circ} \mathrm{W}\right)$ the seasonal variability of surface chlorophyll exhibits very different patterns from what is observed in the high latitudes of the North Atlantic. In particular, no strong phytoplankton bloom is observed. Chlorophyll concentrations are maximum during winter when the deep mixed layer injects nutrients into the surface. Oligotrophic conditions during summer result in very low surface concentrations. The model reproduces the observed seasonal variability with midwinter values

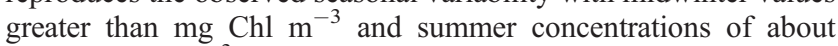
$0.05 \mathrm{mg} \mathrm{Chl} \mathrm{m}^{-3}$.

[48] In the North Pacific Ocean, Station P, despite being located at a comparable latitude to the sites in the North Atlantic Ocean, presents a rather different situation. Neither the observations nor the model show the development of a spring phytoplankton bloom. Chlorophyll concentrations remain relatively homogeneous close 
Table 3. Measurements of pDMSP at Several Locations at the Surface With Computed Concentrations at the Same Time Periods and Areas $^{\mathrm{a}}$

\begin{tabular}{|c|c|c|c|c|c|c|c|c|}
\hline \multirow[t]{2}{*}{ Locations } & \multirow[t]{2}{*}{ Time Period } & \multicolumn{3}{|c|}{ Measurements } & \multicolumn{3}{|c|}{ Model } & \multirow[t]{2}{*}{ Source $^{b}$} \\
\hline & & $\begin{array}{c}\text { Mean, } \\
\text { mmol g }^{-1}\end{array}$ & Range & $\sigma$ & $\begin{array}{c}\text { Mean, } \\
\text { mmol g }\end{array}$ & Range & $\bar{\sigma}$ & \\
\hline NE Atlantic & June & 96.7 & $10.8-280$ & 47.4 & 97.9 & $15.5-310.4$ & 56 & 1 \\
\hline \multirow[t]{2}{*}{ Southern Ocean } & spring & 11 & $0-61$ & $\ldots$ & 28.4 & $0-57.6$ & $\ldots$ & 2 \\
\hline & summer & 13 & $0-102$ & $\ldots$ & 21 & $0-99.2$ & $\ldots$ & 2 \\
\hline \multirow[t]{2}{*}{ Weddell Sea } & spring & 11.1 & $0.4-46.1$ & $\ldots$ & 18.3 & $5.5-36.8$ & $\ldots$ & 3 \\
\hline & summer & 12.5 & $1.5-75$ & $\ldots$ & 17.5 & $4.7-77.2$ & $\ldots$ & 3 \\
\hline Galapagos plume & fall & 45.3 & $19-78.4$ & $\ldots$ & 50.1 & $35.3-71.8$ & $\ldots$ & 4 \\
\hline
\end{tabular}

${ }^{\mathrm{a}}$ All concentrations are in $\mathrm{nM}$.

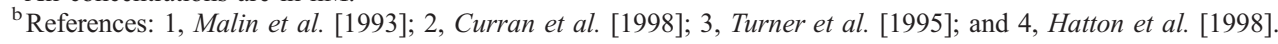

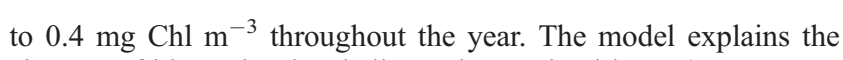
absence of bloom by the shallow winter mixed layer (at most 100 $\mathrm{m}$ deep), which ensures the maintenance of a high standing stock of zooplankton during winter. The resulting intense grazing prevents phytoplankton from blooming in spring and summer. This control by grazing is one of the explanations for high-nutrientslow-chlorophyll areas [Frost, 1987]. Farther South, at HOT $\left(21^{\circ} \mathrm{N}\right.$, $158^{\circ} \mathrm{W}$ ) the situation is relatively similar to that of BATS. Chlorophyll concentrations always remain low because of a very strong nutrient limitation. The model nicely reproduces the observed values. Furthermore, both the model and the observations exhibit a small seasonal cycle, with minimum concentrations in October and maximum concentrations around December.

[49] Finally, at KERFIX $\left(50^{\circ} \mathrm{S}, 68^{\circ} \mathrm{E}\right)$ in the Southern Ocean the model predicts chlorophyll concentrations that are in reasonable good agreement with the observations except during the bloom period. Neither the timing nor the amplitude of the bloom is correctly resolved by the model. First, chlorophyll concentrations start to increase about 1 month earlier than what the data suggest. This time lag may be due to a too early shoaling of the predicted mixed layer. Second, the bloom is largely underestimated since the predicted maximum concentration is about $0.6 \mathrm{mg} \mathrm{Chl} \mathrm{m} \mathrm{m}^{-3}$, whereas the observed values reach nearly $1 \mathrm{mg} \mathrm{Chl} \mathrm{m}^{-3}$.

\section{DMS and pDMSP Distributions}

\subsection{The pDMSP}

[50] Unfortunately, relatively little information exists on the distribution of pDMSP on a global scale. In particular, contrary to what is available for DMS (see section 6.2), no global map of pDMSP concentrations has been constructed from a database. Here we present a comparison of observed and modeled pDMSP concentrations in various areas of the ocean where measurements were available to us (Table 3).

[51] In the North Atlantic Ocean, pDMSP concentrations are on average high both in the model and in the observations during June. The model is rather close to the observed mean pDMSP level with a simulated value of $97.9 \mathrm{nM}$ relative to $96.7 \mathrm{nM}$ in the data. The high observed and simulated pDMSP concentrations are associated with strong blooms of phytoplankton. Furthermore, the observed variability of the pDMSP distribution in this area is well reproduced by the model. Both the deviation and the range of the predicted pDMSP concentrations are close to what is observed: 58 and $15.5-310 \mathrm{nM}$ in the model and 47 and $11-280 \mathrm{nM}$ in the data, respectively.

[52] In the Southern Ocean the situation is rather different. Observed pDMSP concentrations are on average much lower, with a mean of only about $12 \mathrm{nM}$ during spring and summer, which is about 8 times less than in the North Atlantic Ocean during June. The phytoplankton blooms are generally less intense or even absent in the Southern Ocean because of limitations by iron or silicate [Jacques, 1983; de Baar et al., 1995] or because of unfavorable light regimes [Goose and Hecq, 1994]. Furthermore, the phytoplankton biomass is generally dominated by diatoms, which are poor producers of pDMSP and DMS [Meyerdierks et al., 1997]. Unlike in the North Atlantic, the model overestimates the observed pDMSP concentrations. However, it is able to produce much lower values in the Southern Ocean than in the North Atlantic, in agreement with observations. Furthermore, the range of the observed pDMSP concentrations is correctly simulated.

[53] Finally, in the western equatorial Pacific Ocean, pDMSP concentrations are on average high both in the model and in the observations despite the fact that they are about half the levels observed in the North Atlantic Ocean. The model is relatively close to the observations with a predicted mean concentration of 50.1 $\mathrm{nM}$ compared to $45.3 \mathrm{nM}$ in the data. These elevated pDMSP levels are associated with significant TChl $a$ concentrations observed near the Galapagos Island. The observed variability in pDMSP is underestimated by the model, especially for the minimum observed concentrations.

\subsection{DMS}

6.2.1. Global distribution. [54] Kettle et al. [1999] have proposed a global monthly mean climatology of surface DMS. This climatology has since been updated by new measurements from Belviso et al. [2000] and Sciare et al. [1999]. It is constructed from over 17,000 DMS measurements made available from scientists or digitized from publications. These data were then assembled using the scheme of Conkright et al. [1994] to create an annual mean surface map of DMS. The resulting maps should be considered with caution since in many regions, data are rare if not nonexistent. This is especially the case for the Indian and southwest Pacific Oceans. Despite this limiation this climatology represents a useful means to validate the model results on a global scale.

[55] The databased and simulated maps for annual mean sea surface concentrations of DMS are given on Figure 8. Both present the same general patterns. Low concentrations of DMS are found in the subtropical gyres where biological activity is rather small. Upwelling areas like the equatorial Pacific Ocean or the upwellings off Guinea and Angola show higher DMS levels, generally exceeding $3 \mathrm{nM}$. In the western part of the equatorial Pacific Ocean the predicted DMS concentrations are about twice as high as in the database map. In this region the model-simulated biological activity is too intense because it does not include limitations by nutrients such as iron or silicate, which play a crucial role in this region [Dugdale and Wilkerson, 1998; Coale et al., 1996]. Conversely, farther east, the predicted DMS concentrations seem to be underestimated. Despite the fact that no pDMSP measurements were available to us in this area the overestimated simulated chlorophyll concentrations (see Figure 6) do not suggest that the model underpredicts pDMSP there. In fact, large cell (diatoms) growth is limited by iron representing not much more than $10 \%$ of the total phytoplankton biomass [Chavez et al., 1991; Murray et al., 1994]. 
a)

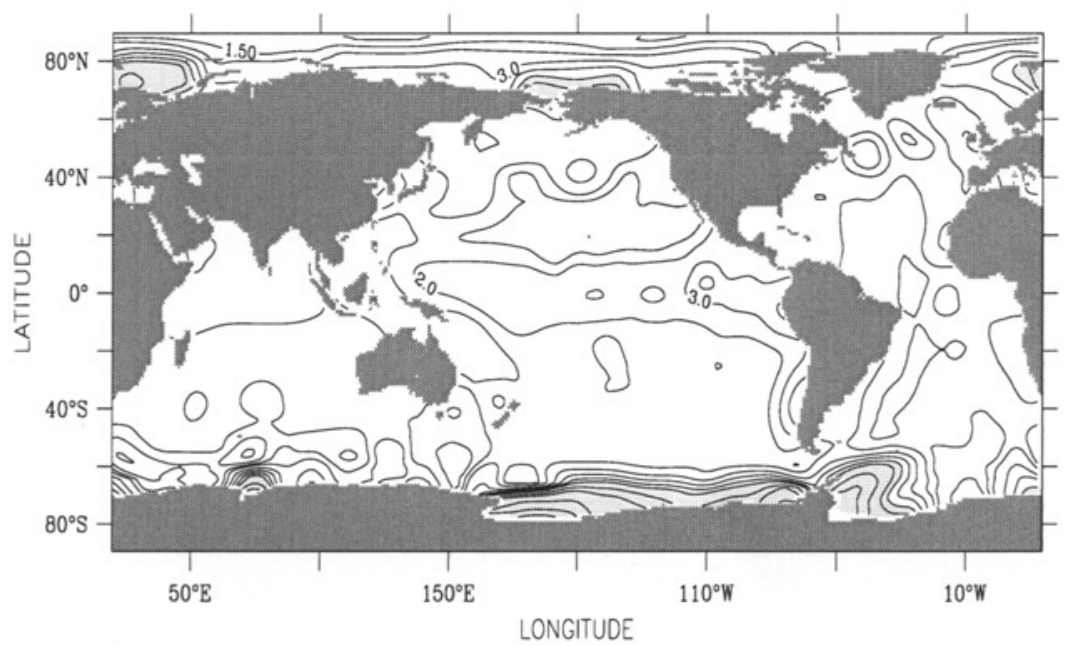

b)

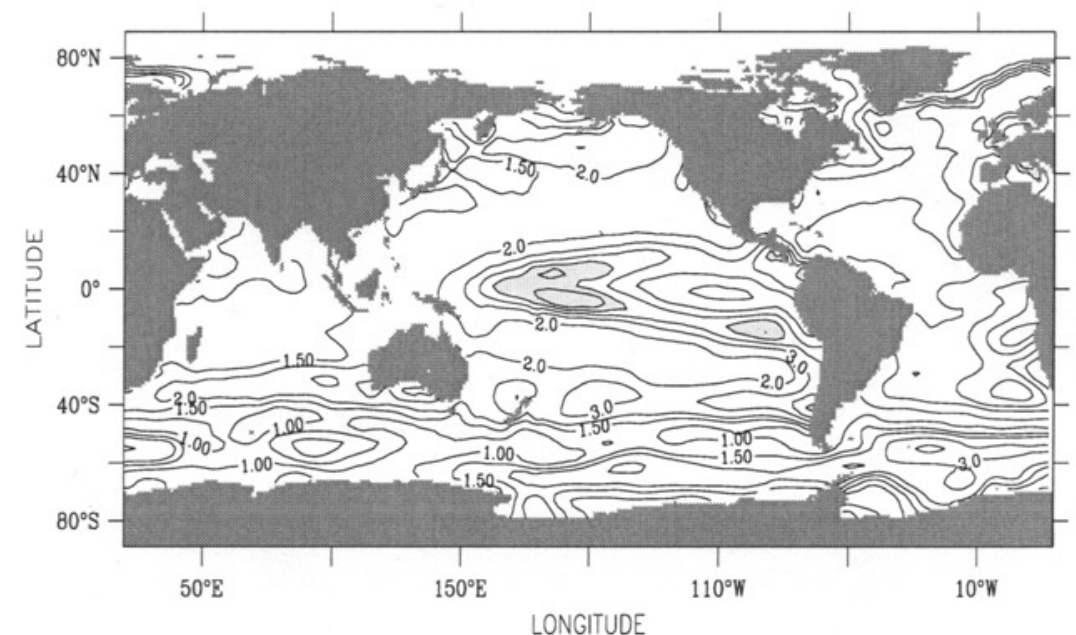

Figure 8. Annual mean of the DMS distribution (in $\mathrm{nM}$ ) at the sea surface for (a) the climatology proposed by Kettle et al. [1999] and (b) IPSL-OCCM2. Isolines spacings are 0.5 between and 2, 1 between 2 and 5, 2 between 6 and 10,5 between 10 and 30 , and 10 between 30 and 50 .

This means an Fp ratio of $<0.1$. The modeled silica ratio is about 0.15 , producing DMS-to-pDMSP ratios that are too low.

[56] The polar oceans exhibit very high DMS concentrations, especially in the Southern Ocean where these concentrations reach $10 \mathrm{nM}$ in the databased map, mainly in the Ross and Weddell Seas. These high values are a result of the strong phytoplankton blooms occurring during spring and summer. In particular, intense blooms of Phaeocytis, which are very efficient DMS producers, have been observed along the Antarctic coast [DiTullio and Smith, 1995]. In the model these high concentrations are not correctly resolved. Part of the problem is due to very high simulated silica ratios (around 0.9) near Antarctica where silicate concentrations are the highest. Consequently, predicted pDMSP levels remain modest, even during the bloom period. However, the very high DMS concentration in the database annual mean map may be due to a sampling bias in these regions since most of the measurements have been made there during the summer months.

[57] A feature simulated by the model is not apparent in the databased map, except perhaps in the Indian Ocean. The model predicts DMS concentrations of more than $2 \mathrm{nM}$ in the subantarctic/subtropical convergence zone around $40^{\circ} \mathrm{S}$. In the database these concentrations are rather low, remaining below $1.5 \mathrm{nM}$. Rather than a deficiency of the model, the lack of observations may explain the discrepancy in this region. In the database, only very few data are available in this latitudinal band of the Indian and Pacific sectors of the Southern Ocean. Recently published data show very elevated DMS concentrations in the subtropical convergence zone of the Indian Ocean, supporting, at least in this region, the model predictions [Sciare et al., 1999]. Despite being now included in the most recently released version of the database these data are not sufficient enough to increase substantially DMS concentrations in the frontal regions.

6.2.2. Comparison along observed transects. [58] In section 6.2.1 we compared simulated global distribution of DMS with the reconstruction of Kettle et al. [1999]. This type of validation offers a means to validate the model on the global scale to climatological maps. However, because of the scarcity of the data, the technique applied by Kettle et al. [1999] to build their climatological maps introduces uncertainties that may affect the validity of the validation. In particular, we noticed that the databased reconstruction does not show strong DMS concentrations in the frontal regions of the Southern Ocean, whereas recent observations and the model do suggest such strong levels. Additionally, as most of 
a)

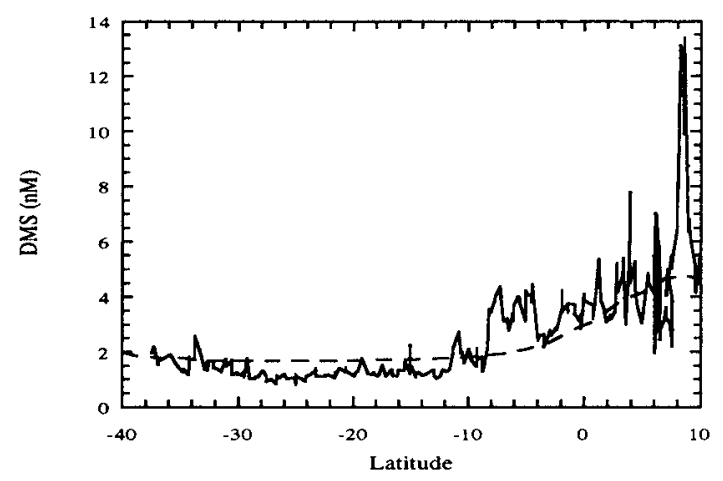

b)

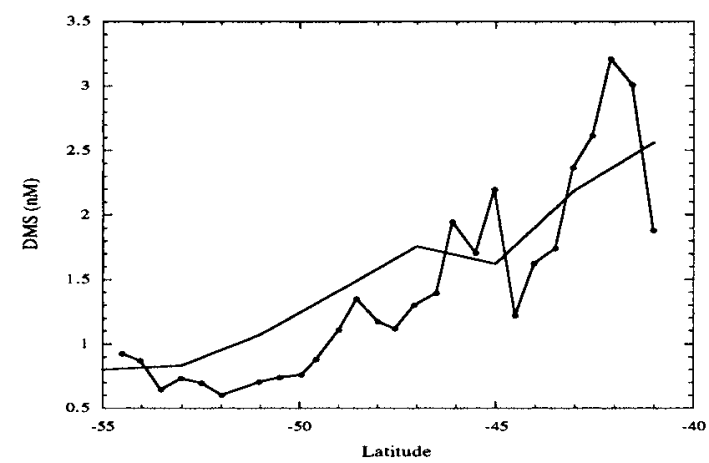

c)

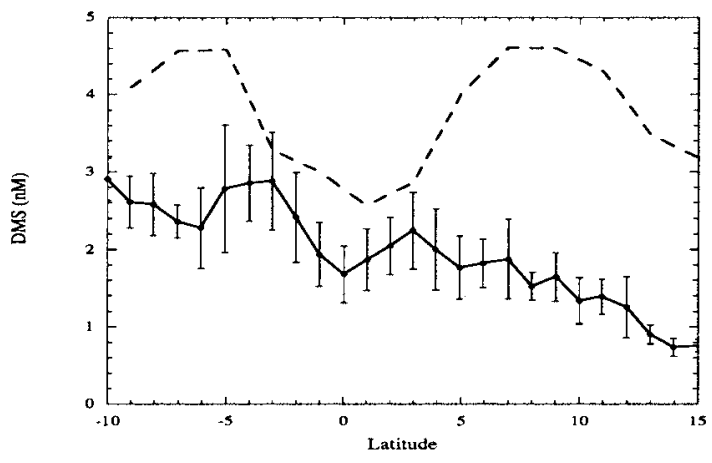

Figure 9. Variation of surface DMS (nM) along (a) $18^{\circ} \mathrm{S}$ in February-March 1991 , (b) $145^{\circ} \mathrm{E}$ in November-December, and (c) $155^{\circ} \mathrm{W}$ in February-March 1983. Solid lines show the observations; dashed lines represent model results. Error bars are displayed when available.

the observations were performed during summer, annual mean DMS concentrations may be biased toward values that are too high.

[59] A more robust means to evaluate the model is to compare predicted DMS fields to direct measurements. Such a comparison is displayed in Figure 9. Three different transects have been selected from the available data sets collected by Kettle et al. [1999], which are representative of three different oceanic regions: the first is just south of the equator in the Atlantic Ocean in February-March 1991 [Andreae et al., 1994]; the second is across the equatorial Pacific Ocean in February-March 1983 [Bates et al., 1987]; and the last one is in the Southern Ocean in December [De Bruyn et al., 1998].

[60] In the Atlantic Ocean the data show a strong zonal gradient in DMS concentrations, which is quite nicely reproduced by the model (Figure 9a). DMS levels are rather low, around $1 \mathrm{nM}$ in the western part until $10^{\circ} \mathrm{W}$. Along the American coast, concentrations are slightly higher resulting from a quite higher biological activity observed in this region. East of $10^{\circ} \mathrm{W}$, DMS levels increase continuously when moving eastwart and reach about $4 \mathrm{nM}$ along the African Coast. The model succeeds in reproducing this eastward increase. The high values are related to the intense biological activity due to the upwelling in the dome of Angola. The observations show a strong mesoscale variability especially in the eastern part of the transect where DMS concentrations may be as high as $13 \mathrm{nM}$. Such high sensitivity of DMS to mesocale circulation has been discussed by Belviso et al. [2000]. Since the model does not resolve the eddies, such variability cannot be reproduced.

[61] In the Southern Ocean, observations show a three-fold decrease of DMS concentrations from $40^{\circ}$ (near the Tasmanian Island) to $55^{\circ} \mathrm{S}$. Such a decrease is roughly simulated by the model. The model suggests two explanations for this southward decrease. First, chlorophyll concentrations are higher in the northern part of the transect because of a shallower mixed layer, which provides more favorable light conditions. Second, the predicted plankton community is more diatom-dominated near $55^{\circ} \mathrm{S}$ than in the northern part of the transect because more silicate is available. Consequently, pDMSP concentrations in the surface seawater are lower. Additionally, a higher proportion of diatoms means a higher silica ratio, which is a lower DMS-to-pDMSP ratio (at least until a silica ratio of about 0.6 , which is the case here). Despite the general good agreement between the model and the data, modeled DMS concentrations are underestimated by a factor of about 2 in the intermediate part of the transect. However, the data available to us were not sufficient to investigate the reasons for such a discrepancy.

[62] In the equatorial Pacific Ocean the agreement between the observations and the model predictions is not very good. The general trend suggested by the observations for this period is higher DMS concentrations in the Southern Hemisphere, where they average $2.5 \mathrm{nM}$, than in the Northern Hemisphere, where they decrease northward to $0.7 \mathrm{nM}$ at $15^{\circ} \mathrm{N}$. Such a trend is not yet simulated by the model, which tends to predict high values around $3 \mathrm{nM}$ both north and south of the equator. Thus, in the northern part of the equatorial region, DMS concentrations are largely overpredicted, whereas south of $5^{\circ} \mathrm{N}$, they are in general agreement with the observations. In fact, all over this domain the model simulates chlorophyll concentrations that are much too high (see Figure 8) because the geochemical species other than phosphate, which have been proven to be play an important role in limiting productivity, are not included in the model. At the equator and in the southern part of the transect these overly elevated concentrations are compensated by silica ratios that are too high, which leads to underestimated DMS-to-pDMSP ratios. On the other hand, in the northern sector, silica ratios are very low $(<0.05)$ associated with overestimated chlorophyll concentrations, resulting in these very high DMS concentrations.

6.2.3. Seasonal cycle of DMS. [63] DMS is expected to show large seasonal variations, especially in the high latitudes, as it is a product of the biological activity. Unfortunately, repeated measurements at the same location during several successive years are very rare. However, Kettle et al. [1999] have constructed monthly maps of the DMS distribution from a database of existing measurements. To compute monthly quantities, they have averaged DMS concentrations over 57 biogeochemical provinces as defined by Longhurst et al. [1995]. Figure 10 displays the seasonal variations of DMS deduced from these monthly maps and as predicted by the model for nine regions corresponding to the northern high latitudes, the middle and low latitudes, and the equatorial regions of the Pacific and Atlantic Oceans as well as the Southern Ocean. The Indian Ocean was not included in this comparison because data used to construct the monthly maps are very sparse in this region. We chose this type of 


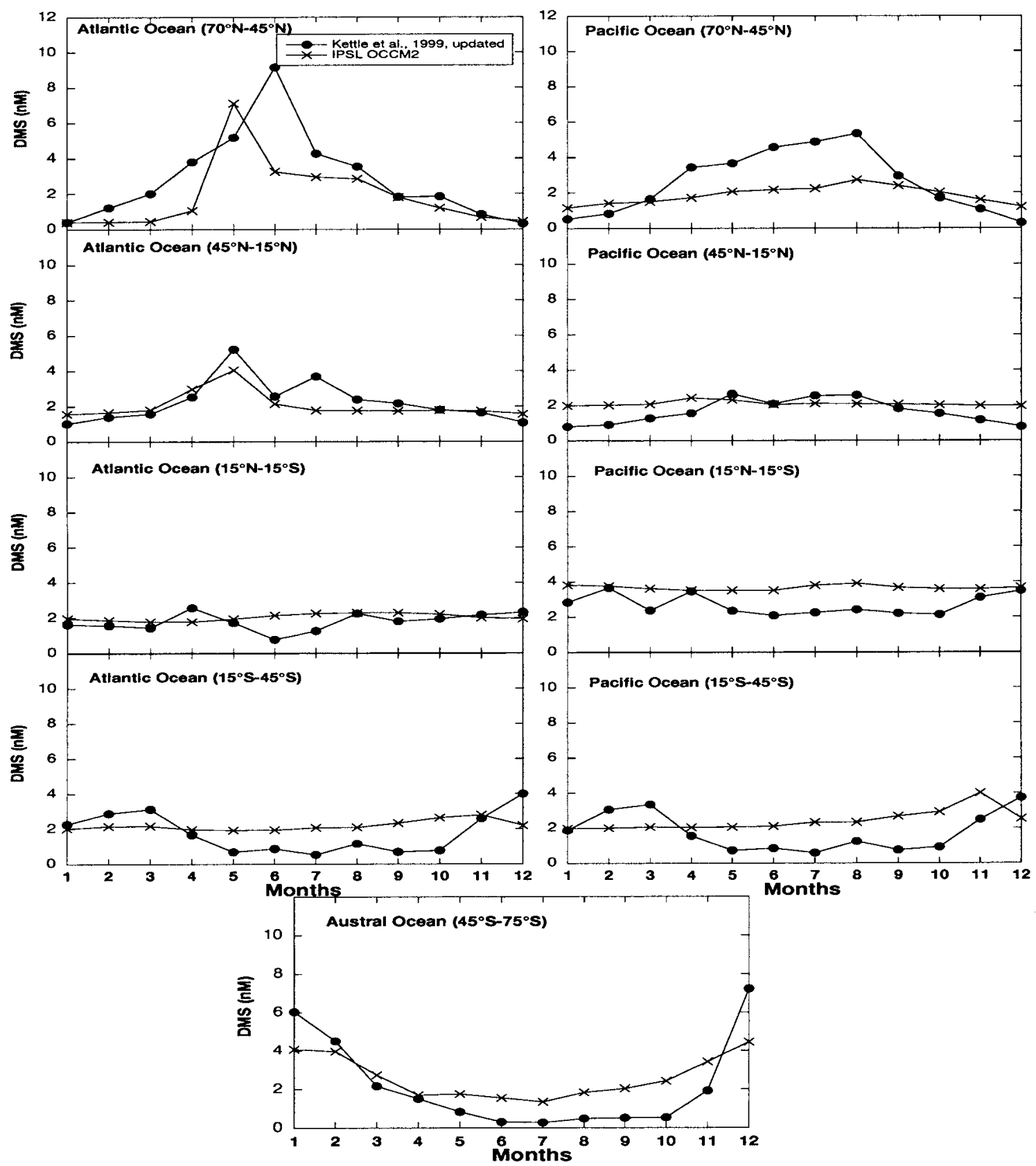

Figure 10. Seasonal variations of sea surface DMS concentrations (in $\mathrm{nM}$ ). The solid line with the solid circles indicates the climatology from Kettle et al. [1999]; the solid line with the open circles indicates the model results. DMS concentrations are averaged over nine different provinces corresponding to the northern high latitudes, the middle and low latitudes, and the equatorial regions of the Pacific and Atlantic Oceans, and the Southern Ocean.

validation rather than a comparison at selected stations to be more consistent with the technique used by Kettle et al. [1999] to compute the databased maps.

[64] This comparison first confirms that the model reproduces reasonably well the average order of magnitude of the observed DMS concentrations over the global ocean. DMS concentrations are generally low around $2 \mathrm{nM}$ for most provinces. In the high and middle latitudes of the Atlantic Ocean, DMS levels begin to increase in April and May to peak in June at about $10 \mathrm{nM}$. In the Southern Ocean this increase is shifted by about 6 months. The model underestimates by about two-fold the amplitude of the seasonal variations both in the North Atlantic Ocean and in the Southern Ocean. In the latter ocean the observed high summer values are related to intense Phaeocystis blooms, at least in the
Ross Sea, which are not resolved by the model (see section 6.2.2). In the high latitudes of the North Pacific Ocean the small seasonality of phytoplankton concentrations leads to only weak seasonal variations of DMS.

[65] In the high latitudes of the North Atlantic Ocean the modeled maximum concentrations are reached about 1 month earlier than in the observations. The explanation for this time lag is not clear. Comparison at stations or to satellite data shows that the model simulates correctly both the amplitude and the timing of the spring phytoplankton bloom in this region. However, intense localized blooms of Coccolithophores, which are efficient DMS producers, have been evidenced in the northeast Atlantic after the spring diatom blooms have depleted inorganic nutrients [Holligan, 1987]. These summer blooms are not simulated by thef model. One 
Table 4. Regional Sea-to-Air Fluxes of DMS ${ }^{\mathrm{a}}$

\begin{tabular}{cccc}
\hline Latitude & $\begin{array}{c}\text { Global Ocean Surface, } \\
10^{12} \mathrm{~m}^{2}\end{array}$ & \multicolumn{2}{c}{$\begin{array}{c}\text { Global DMS flux } \\
\text { Tg S yr }^{-1}\end{array}$} \\
\cline { 3 - 4 } & & L\&M86 & W92 \\
\hline $90^{\circ}-40^{\circ} \mathrm{S}$ & 73 & 3.2 & 5.2 \\
$40^{\circ}-15^{\circ} \mathrm{S}$ & 79 & 5.3 & 8 \\
$15^{\circ}-15^{\circ} \mathrm{N}$ & 101 & 4.1 & 6.9 \\
$15^{\circ}-40^{\circ} \mathrm{N}$ & 61 & 2.7 & 4 \\
$40^{\circ}-90^{\circ} \mathrm{N}$ & 32 & 1.7 & 2.6 \\
Total ocean & 347 & 17 & 26.7 \\
\hline
\end{tabular}

${ }^{a}$ Columns L\&M86 and W92 refer to different formulations used for computing the air-sea gas exchange coefficient. L\&M86: Formulation proposed by Liss and Merlivat [1986] (see text for precisions on the correction applied to the wind fields used to compute these coefficients); W92: Formulation of Wanninkhof [1992]

should also keep in mind that the sparsity of the data may introduce some bias in the databased maps.

[66] Equatorial regions are characterized by only small changes of DMS, both in the Atlantic and the Pacific. This small seasonality is well reproduced by the model. These variations are driven by changes in the rates of the equatorial upwellings. Finally, in the low latitudes and midlatitudes of Southern Hemisphere the model simulates correctly the average level of DMS. However, both the amplitude and the timing of the maximum DMS levels are unrealistic. In particular, as in the North Atlantic Ocean, the predicted peak of DMS occurs much too early. This problem may be related to the similar shift observed for chlorophyll concentrations at KERFIX station.

\section{Global Flux of DMS}

[67] The main aim of this study was to estimate the global flux of DMS to the atmosphere. Additionally, the regional distribution of this flux and its seasonal variations can be determined by the model presented here. Computation of this flux relies on the classical parameterization, which assumes that the flux is proportional to the difference of concentrations at the air-sea interface and to a gas exchange coefficient. The value of this coefficient is calculated as a function of wind speed using the relationship proposed by Liss and Merlivat [1986] and the climatological wind fields of Hellermann and Rosenstein [1983]. As the atmospheric concentration of DMS is generally 2 orders of magnitude lower than in the seawater, we only consider here DMS outflux to the atmosphere.

[68] Nevertheless, computation of this gas exchange coefficient is still a matter of debate. Studies suggest that the relationship proposed by Liss and Merlivat [1986] may underestimate the fluxes by a factor of 2 [Wanninkhof, 1992]. Part of this difference arises because of the wind fields used in these calculations. Gas exchange coefficients determined using climatological winds are generally lower than those obtained with shipboard winds. To overcome this problem, we have applied the same correction as Wanninkhof [1992], assuming that the distribution of instantaneous wind speed follows a Rayleigh probability distribution function. For comparison we have also computed the DMS fluxes using the formulation (equation (2)) of Wanninkhof [1992].

[69] The model predicts an annual mean global flux of DMS to the atmosphere of $17 \mathrm{Tg} \mathrm{S} \mathrm{yr}^{-1}$ (Table 4). With the Wanninkhof [1992] formulation the flux is about $60 \%$ higher, reaching $26.7 \mathrm{Tg}$ $\mathrm{S} \mathrm{yr}^{-1}$. Estimates of this flux found in the literature exhibit a large range of values. From the compilation of DMS data, Andreae [1990] proposed a much higher outflux with values between 19 and $50 \mathrm{Tg} \mathrm{S} \mathrm{yr}^{-1}$ using the Liss and Merlivat [1986] formulation for the gas exchange coefficient. Bates et al. [1987] measured surface DMS concentrations from over 1000 samples taken in the
North Pacific Ocean during 4 successive years. Separating this data into winter and summer conditions, they extrapolated their measurements by regional areas to the global ocean to determine the net global DMS flux to the atmosphere. This computation yields a much lower number of about $16 \mathrm{Tg} \mathrm{S} \mathrm{yr}^{-1}$ also with the Liss and Merlivat [1986] formulation. Besides these estimates based on few measurements in seawater, atmospheric models of the sulfur cycle have been used to study the atmospheric distribution of the sulfur compounds. These models include DMS using available estimates of the ocean source as an input. They generally achieve consistency with measurements when a rather low source of DMS is applied ranging between 17 and $22 \mathrm{Tg} \mathrm{S} \mathrm{yr}^{-1}$ [Pham et al., 1995; Feichter et al., 1996; Chin et al., 1996]. Otherwise, a missing removal process of atmospheric DMS should be included in these models [Chin et al., 1996].

[70] Our estimate of the global flux of DMS relies on the prediction of a model. Assessing the uncertainties associated with this model is rather difficult. They may be related to the predicted circulation, to the simulated biological parameters used as inputs in the parameterization of DMS (i.e., TChl $a$ and the Fp ratio), and to the equations from which we derive DMS. For the latter a set of two sensitivity runs we performed may give some clues on the sensitivity of the predicted global flux of DMS. The first test corresponds to the use of a different regression fit for diagnosing DMS-to-pDMSP ratios from the Fp ratios based on a parabolic function. The global flux was estimated to $17.5 \mathrm{Tg} \mathrm{S} \mathrm{yr}^{-1}$, which is about 3\% higher than our best estimate. In the second sensitivity experiment the fit for Fp ratios lower than 0.6 (equation (1)) is also applied for Fp ratios higher than 0.6. This means that the rather arbitrary fit we chose for high $\mathrm{Fp}$ ratios is abandoned. The difference in the global flux of DMS is only $6 \%$. Thus, on the global scale our estimate of the DMS flux seems to be rather robust relative to the parameterization of DMS, at least according to these limited tests.

[71] Table 4 also shows the predicted annual air-to-sea fluxes of DMS integrated over five latitudinal bands corresponding roughly to the equatorial regions, the midlatitudes, and the high latitudes of each hemisphere. The low latitudes and midlatitudes of the Southern Hemisphere are the strongest source of DMS. In this domain the very low chlorophyll concentrations are compensated by very low silica ratios. The low values of this ratio increase both the pDMSP-to-chlorophyll and the DMS-to-pDMSP ratios, resulting in significant DMS concentrations in the seawater. Furthermore, this domain includes part of the region located between the subtropical/subantarctic convergence and the Polar Front where high concentrations of DMS are simulated by the model. Despite similar conditions the predicted flux of DMS in the low and middle latitudes of the Northern Hemisphere is about half less. The smaller area partly explains this difference. Furthermore, the elevated DMS concentrations simulated by the model between $30^{\circ}$ and $50^{\circ} \mathrm{S}$ are not simulated in the corresponding region of the North Pacific Ocean where DMS concentrations remain modest throughout the year (see Figure 10).

[72] The equatorial regions are also a significant source of DMS for the atmosphere. The major contributor to this flux is the equatorial Pacific Ocean, which accounts for about $70 \%$ of this outgassing. Despite its strong intensity this source presents large spatial heterogeneities. Most of the degassing occurs in the western part and between $5^{\circ}$ and $15^{\circ}$ both south and north of the equatorial Pacific, where high concentrations of chlorophyll are associated with low silica ratios to produce high DMS concentrations (see Figure 8). On the other hand, the central and eastern parts of the equatorial upwelling exhibit much lower fluxes of DMS. The higher silicate concentrations lead to a more diatom-dominated plankton community, which combines with low gas exchange coefficients to induce this more modest flux. In the central Pacific Ocean $\left(165^{\circ}-145^{\circ} \mathrm{W}, 10^{\circ} \mathrm{S}-10^{\circ} \mathrm{N}\right)$, Bates et al. [1993] have estimated the mean DMX flux to $7.7 \mu \mathrm{mol} \mathrm{m}^{-2} \mathrm{~d}^{-1}$ from measure- 


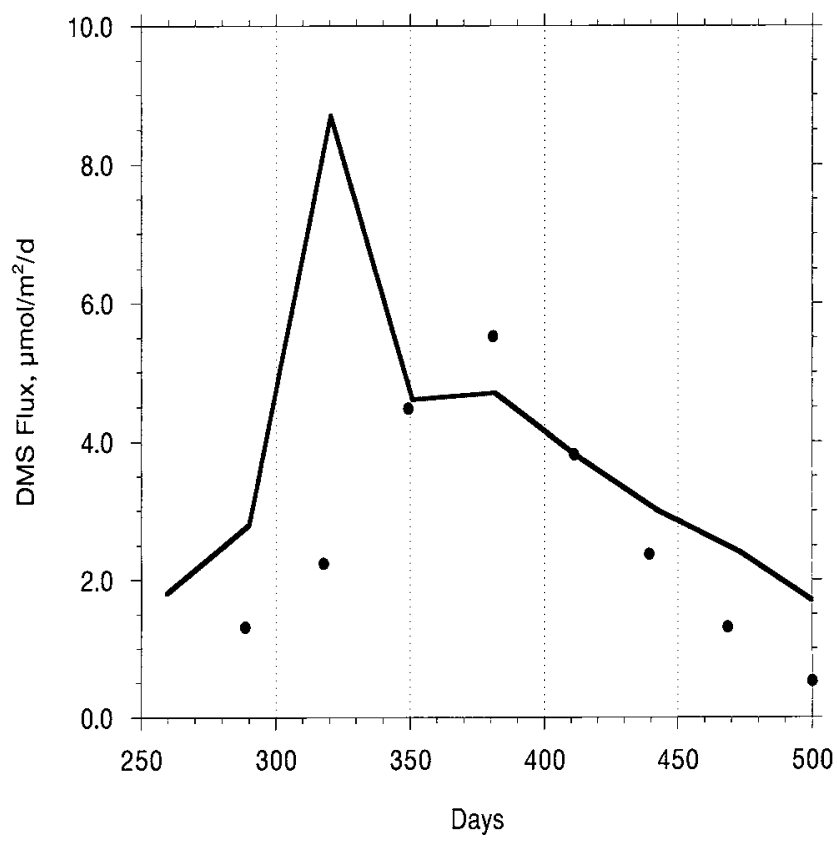

Figure 11. Atmospheric and ocean model predictions for sea-toair fluxes of DMS (in $\mu \mathrm{mol} \mathrm{m} \mathrm{m}^{-2} \mathrm{~d}^{-1}$ ) in the Southern Ocean near Cape Grim (see text for explanation). The solid circles denote the atmospheric estimates; the solid line shows the ocean-predicted fluxes.

ments made during the Soviet-American Gas and Aerosal Experiment 3 (SAGA3) expedition. The corresponding flux predicted by the model is $7.8 \mu \mathrm{mol} \mathrm{m} \mathrm{m}^{-2} \mathrm{~d}^{-1}$. It may seem surprising that both estimates are so similar since in the same region the model significantly overestimates DMS concentrations. In fact, we used climatological wind fields from Hellermann and Rosenstein [1983] to compute the air-sea gas exchange coefficients. In this climatology the average wind speeds for the central Pacific Ocean range from 5 to $7 \mathrm{~m} \mathrm{~s}^{-1}$, whereas during SAGA3 the observed wind speeds were between 8 and $12 \mathrm{~m} \mathrm{~s}^{-1}$. Thus, lower wind speeds in the model produce gas exchange coefficients that are too low, even with the correction we applied to convert averaged climatological wind speeds into instantaneous wind speeds. Such underestimated wind speeds partly compensate the overestimated DMS concentrations to simulate a flux of DMS in very close agreement with the observations.

[73] In the high latitudes of both hemispheres, DMS fluxes are more modest. This flux mainly results from the strong biological activity predicted by the model in spring and summer. In the Southern Ocean, half of the total degassing occurs between $40^{\circ}$ and $50^{\circ} \mathrm{S}$ where the model predicts elevated DMS concentrations. Farther south, as a result of the very high silicate concentrations, most of the predicted biological production is based on diatoms. Consequently, DMS concentrations and thus DMS fluxes are very small. There are very few estimates of this flux in the Southern Ocean because of the paucity of the data in this remote area. Berresheim [1987] estimated that the annual emission from the Antarctic Ocean (south of $50^{\circ} \mathrm{S}$ ) was about $2.7 \mathrm{Tg} \mathrm{S} \mathrm{yr}^{-1}$ using the Liss and Merlivat [1986] formulation for the gas exchange coefficient. From data performed through the Drake Passage to the Bellinghausen Sea, Turner et al. [1995] suggested a flux ranging from 2.8 to $14.8 \mathrm{Tg} \mathrm{S} \mathrm{yr}^{-1}$ for the same ocean. Our predicted DMS emission for the Antarctic Ocean is $1.9 \mathrm{Tg} \mathrm{S} \mathrm{yr}^{-1}$, which is at least $50 \%$ lower than these databased estimates. The underpredicted DMS concentrations along the Antarctic coast, and especially in the Ross and Weddell Seas, probably explain this discrepancy (Figure 8). However, estimates of the DMS flux in this region should be considered with caution as very large uncertainties still remain in the average levels and in the seasonal cycle of DMS. In particular, most of the previous estimates may be biased by the large numbers of measurements performed at coastal ice edge areas where large phytoplankton blooms are observed [Jochem et al., 1993]. Recent studies conducted in the open ocean suggest that the Southern Ocean may be a relatively small source of DMS [Meyerdierks et al., 1997].

[74] Direct validation of the fluxes is not yet feasible because they cannot yet be measured directly. A possible means to evaluate the predicted fluxes is to compare the simulated DMS concentrations to observed values. Measurements of atmospheric concentrations of DMS provide an alternative means to constrain the predicted DMS fluxes. Of additional interest is the fact that unlike ocean measurements, atmospheric measurements integrate ocean fluxes over a large geographical area. This approach has proven to be very powerful for $\mathrm{CO}_{2}$ and $\mathrm{O}_{2}$ fluxes with the atmospheric potential oxygen tracer [Stephens et al., 1999]. Unfortunately, unlike $\mathrm{CO}_{2}$ or $\mathrm{O}_{2}$, DMS is not a passive tracer in the atmosphere. Thus studying its atmospheric distribution requires an atmospheric sulfur model, which introduces its own uncertainties [Pham et al., 1995; Chin et al., 1996]. Furthermore, such a model was not available to us. Nevertheless, Gabric et al. [1995] has reconstructed DMS fluxes from measurements made at Cape Grim [Ayers et al., 1991] using a simple boundary layer box model to model the transformation of DMS in the atmosphere. These estimates are very interesting as there are very few oceanic observations of DMS in the Southern Ocean.

[75] Figure 11 shows these estimates by Gabric et al. [1995] along with model-predicted fluxes for that region. We crudely assumed that DMS atmospheric concentrations can be affected by DMS fluxes in an upwind region whose horizontal extent is $10^{\circ}$ longitude by $10^{\circ}$ latitude. We thus averaged predicted DMS fluxes over that region to compare them with the estimated fluxes. To be consistent with Gabric et al. [1995], we also used monthly averaged wind speeds without the correction proposed by Wanninkhof [1992]. The results are quite encouraging. The model is able to reproduce the high summer values resulting from the intense biological production and the low winter values. However, the model predicts an unrealistic peak in November, which is not apparent in the estimates. This suggests that the model predicts a spring phytoplankton bloom in this region that is too intense or that occurs too early in the year. Comparison of simulated chlorophyll concentrations with observations at KERFIX station (Figure 7) has shown that the model predicts a spring phytoplankton bloom that occurs about 1 month too early.

\section{Conclusions}

[76] Distribution and seasonal variations of DMS and pDMSP result from the biological activity in the ocean. A simple ocean global carbon cycle model (the IPSL-OCCM2 model) including an explicit representation of plankton dynamics has been used as a basis for modeling the global distributions of DMS and pDMSP. Only one set of parameters has been selected for the global ocean, as far as possible, from the literature, thus avoiding regional tuning. IPSL-OCCM2 is generally able to reproduce observed seasonal variations of phytoplankton such as strong spring blooms in the North Atlantic Ocean. The model also explains the lack of strong phytoplankton blooms in the North Pacific Ocean by the relatively shallow mixed layer that maintains substantial levels of zooplankton during winter; a similar result was found by Six and MaierReimer [1996]. However, IPSL-OCCM2 largely overpredicts chlorophyll concentrations in the equatorial Pacific Ocean and, to a lesser extent, in the Southern Ocean, the most likely explanation being that iron or silicate limitations are not considered. In order to improve simulated results in these regions those limitations would have to be included in the model. 
[77] This ocean carbon cycle model IPSL-OCCM2 provides the basis for modeling the global surface distribution of pDMSP and DMS. The parameterizations for these sulfur compounds are not based on mechanistic equations describing the processes that control the production and the removal of these sulphur compounds. Instead, diagnostic relationships have been inferred from data made during several expeditions, which were carried out in contrasted regions of the world oceans. They relate DMS and pDMSP surface concentrations to chlorophyll concentrations and to the Fp ratio, a trophic status ratio that characterizes the relative abundance of microphytoplankton [Claustre, 1994]. As IPSL-OCCM2 only includes one phytoplankton reservoir, a proxy for the Fp ratio, the silica ratio, has been defined, which is based on the relative intensity of the biogenic silica export and reflects the abundance of diatoms. A reasonable agreement with observed regional and seasonal variations of surface pDMSP and DMS is achieved. High production rates of DMS and pDMSP are found in the equatorial Pacific Ocean and in the subantarctic/subtropical convergence. However, simulated seasonal cycles of DMS in the high latitudes are underestimated, especially along the Antarctic coasts where the observed strong summer blooms of Phaeocystis are not correctly resolved by the model. IPSL-OCCM2 predicts a global annual DMS flux that ranges from 17 to $26.7 \mathrm{Tg} \mathrm{S} \mathrm{yr}^{-1}$, depending on the formulation used to compute the gas exchange coefficient. About one third of this flux is located in the subtropical/subantarctic frontal zones, which thus represent a critical region for the sulfur cycle in the atmosphere. These numbers support a modest ocean source of DMS as estimated by Bates et al. [1987] or by atmospheric models [Pham et al., 1995; Feichter et al., 1996; Chin et al., 1996] (between 16 and $22 \mathrm{Tg} \mathrm{S} \mathrm{yr}^{-1}$ ) rather than a strong source as suggested by estimates from Andreae [1990] (from 19 to $50 \mathrm{Tg} \mathrm{S} \mathrm{yr}^{-1}$ ).

[78] Future climate changes that may be induced by human activities are likely to affect significantly the ocean circulation and the marine biological production, and thus the geochemical cycles of carbon and sulphur. Coupled ocean-atmosphere models suggest that increasing $\mathrm{CO}_{2}$ concentrations in the atmosphere can cause a sharp decrease of the thermohaline overturning but also in the equatorial Pacific upwelling [Manabe and Stouffer, 1994; Barthelet et al., 1998]. However, effects of these changes on marine production are not evident. The model of DMS presented in this study provides the means to assess in a coupled ocean-atmosphere model the consequences of a climate change on the release of DMS by the ocean. This question is crucial because, according to the simple computations performed by Watson and Liss [1998], changes in DMS production are likely to have larger impacts on climate than the processes involving $\mathrm{CO}_{2}$.

\section{Appendix A: Description of the Biogeochemical Model P3ZD}

[79] The following system of equations simulates the dynamics of the five variables. For simplicity, effects of advection and diffusion are omitted in these equations:

$$
\begin{aligned}
R_{P / \mathrm{C}} \frac{d \mathrm{PO}_{4}^{3-}}{d t}= & -\mu^{\mathrm{PO}_{4}} P+\varepsilon m_{Z} \frac{Z}{Z_{0}+Z} Z \\
& +\lambda_{\mathrm{DOC}}^{*} \frac{\mathrm{PO}_{4}^{3-}}{K_{\mathrm{DOC}}^{1}+\mathrm{PO}_{4}^{3-}} \frac{\mathrm{DOC}}{K_{\mathrm{DOC}^{2}+\mathrm{DOC}}} \text { DOC, }
\end{aligned}
$$

$\frac{d P}{d t}=(1-\delta) \mu^{\mathrm{PO}_{4}} P-m_{P} \frac{P}{P_{0}+P} P-w_{P} P^{2}-g_{P}(P, \mathrm{POC}) Z-\nu \frac{\partial P}{\partial z}$,

$$
\frac{d Z}{d t}=\sigma\left[g_{P}(P, \mathrm{POC})+g_{\mathrm{POC}}(P, \mathrm{POC})\right] Z-\left(m_{Z}+r_{Z}\right) \frac{Z}{Z_{0}+Z} Z
$$

$$
\begin{aligned}
& \frac{d \mathrm{POC}}{d t}=(1-\sigma)\left[g_{P}(P, \mathrm{POC})+g_{\mathrm{POC}}(P, \mathrm{POC})\right] Z \\
& +(1-\varepsilon) m_{Z} \frac{Z}{Z_{0}+Z} Z+m_{P} \frac{P}{P_{0}+P} P-g_{\mathrm{POC}}(P, \text { POC }) Z \\
& -\lambda_{\mathrm{POC}} \mathrm{POC}-w \frac{\partial \mathrm{POC}}{\partial z}, \\
& \frac{d \mathrm{DOC}}{d t}=\delta \mu^{\mathrm{PO}_{4}} P+r_{Z} \frac{Z}{Z_{0}+Z} Z+\lambda_{\mathrm{POC}} \mathrm{POC} \\
& -\lambda_{\mathrm{DOC}}^{*} \frac{\mathrm{PO}_{4}^{3-}}{K_{\mathrm{DOC}}^{1}+\mathrm{PO}_{4}^{3-}} \frac{\mathrm{DOC}}{K_{\mathrm{DOC}}^{2}+\mathrm{DOC}} \mathrm{DOC}, \\
& \frac{d \frac{\mathrm{Chl}}{\mathrm{C}}}{d t}=\mu^{\mathrm{PO}_{4}}\left(\frac{\mathrm{Ch} 1^{*}}{\mathrm{C}}-\frac{\mathrm{Chl}}{\mathrm{C}}\right) \text {, }
\end{aligned}
$$

with

$$
\begin{gathered}
\mu^{\mathrm{PO}_{4}}=\mu_{\max } L_{m}\left(1-e^{-\alpha I_{\mathrm{par}} \frac{\mathrm{Ch}}{C} / \mu_{\max }}\right) e^{-\beta I_{\mathrm{par}} \frac{\mathrm{Ch}}{C} / \mu_{\max }} \frac{\mathrm{PO}_{4}^{3-}}{K_{\mathrm{PO}_{4}}+\mathrm{PO}_{4}^{3-}}, \\
\mu_{\max }(T)=a b^{c T},
\end{gathered}
$$$$
\frac{\mathrm{Ch} 1^{*}}{\mathrm{C}}=\left[\frac{\mathrm{Chl}^{\mathrm{max}}}{\mathrm{C}}-\left(\frac{\mathrm{Ch}^{\mathrm{max}}}{\mathrm{C}} \frac{\mathrm{Chl}^{\mathrm{min}}}{\mathrm{C}}\right) \min \left(\frac{I_{\mathrm{par}}}{I_{\mathrm{par}}^{\max }}, 1\right)\right] \frac{\mathrm{PO}_{4}^{3-}}{\mathrm{K}_{\mathrm{PO}_{4}}+\mathrm{PO}_{4}^{3-}},
$$

$$
g_{P}(P, \mathrm{POC})=g \frac{p_{P} P}{P_{1}+p_{P} P+p_{\mathrm{POC}} \mathrm{POC}}
$$$$
g_{\mathrm{POC}}(P, \mathrm{POC})=g \frac{p_{\mathrm{POC}} \mathrm{POC}}{P_{1}+p_{P} P+p_{\mathrm{POC}} \mathrm{POC}} .
$$

The growth rate of phytoplankton depends on local conditions of light, nutrients, temperature, and vertical mixing. Nutrient limitation is described by widespread Michaelis-Menten kinetics. Light limitation is parameterized by the formulation proposed by Platt et al. [1980].

[80] The photosynthetic available radiation $\left(I_{\mathrm{par}}\right)$ is computed from a simple light absorption model:

$$
\begin{gathered}
\kappa_{r}=\kappa_{r 0}+\kappa_{c} P \frac{\mathrm{Chl}}{\mathrm{C}}, \\
\kappa_{g}=\kappa_{g 0}+\kappa_{c} P \frac{\mathrm{Ch} l}{\mathrm{C}}, \\
I_{\mathrm{par}}(z)=0.45 I_{0}\left[\frac{1}{2} \exp \left(-\int_{0}^{z} \kappa_{r} d z\right)+\frac{1}{2} \exp \left(-\int_{0}^{z} \kappa_{g} d z\right)\right],
\end{gathered}
$$

where $I_{0}$ is the total irradiance at the surface and 0.45 represents the fraction of this irradiance that is available for photosynthesis. As Taylor et al. [1991], we considered two different wavelengths corresponding basically to the red and the green lights. Light 
attenuation coefficients include a self-shading part due to phytoplankton.

[81] Phytoplankton growth rate is highly sensitive to the depth of the mixed layer [Sverdrup, 1953]. When the mixed layer is deeper than the euphotic zone, production is reduced because phytoplanktonic cells spend time in dark areas. In particular, it is generally believed that the shoaling of the mixed layer is the main factor controlling the timing of phytoplankton blooms. This limitation is parameterized in the model through a coefficient $L_{m}$ following the formulation proposed by André [1990]. This parameterization considers two cases. When the mixed layer is deeper than the euphotic zone, production is reduced. $L_{m}$ linearly decreases from 1 to a threshold value set to 0.5 reached when the mixed layer is twice as deep as the euphotic zone. On the other hand, when the mixed layer is shallower than the euphotic zone, production is not inhibited $\left(L_{m}=1\right)$. In this case, phytoplankton is exposed to a mean $I_{\mathrm{par}}$ over the mixed layer.

[82] Phytoplanktonic cells adapt their $\mathrm{Chl} / \mathrm{C}$ levels to the local conditions they experienced. Studies based on laboratory experiments have shown that this ratio varies with the availability of light and nutrients: phytoplankton increases its $\mathrm{Chl} / \mathrm{C}$ ratio as irradiance decreases or nutrient availability increases [Falkowski et al., 1985]. In the model we represent this variation (equation (8)) following the formulation proposed by Doney et al. [1996]. In this relation, photoadaptation, rather than instantaneous changes, occurs with a timescale given by the specific growth rate [Cloern et al., 1995]. The $\mathrm{C} / \mathrm{Chl}$ ratio is bounded between 37 and $180 \mathrm{mg} \mathrm{C}(\mathrm{mg} \mathrm{Chl})^{-1}$.

[83] In the model, zooplankton is supposed to feed on phytoplankton and detritus (POC). The governing equations for grazing are adapted from Fasham et al. [1990]. A constant fraction (1- $\sigma)$ of ingested food is released as fecal pellets, the remainder being assimilated for zooplankton growth. The zooplankton loss term represents both inorganic excretion and mortality and predation by higher trophic levels. A fraction $\varepsilon$ of this loss is in the form of phosphate. Following Taylor et al. [1997], this term is assumed to be a function of the local nutrient concentration:

$$
\varepsilon=0.3+0.65 \frac{\mathrm{PO}_{4}^{3-}}{K_{\mathrm{PO}_{4}}+\mathrm{PO}_{4}^{3-}} .
$$

This relation results from the general idea that recycling efficiency is expected to increase as nutrients become more depleted. The remainder of the loss term is lost as particulate organic matter.

[84] Detrital material originates from both phytoplankton and zooplankton mortalities, aggregation, and zooplankton fecal pellets. This material is recycled in the model in two different ways: breakdown of detritus to dissolved organic matter and reingestion by zooplankton. The first process is modeled with a first-order kinetics assuming a constant breakdown rate $\lambda_{\text {POC }}$. The detrital sinking speed $w$ is assumed constant everywhere, despite that in reality it may greatly vary depending on the size and type of the material. Here $\lambda_{\mathrm{POC}}$ and $w$ have been set to obtain a remineralization length scale of $100 \mathrm{~m}$, roughly what is observed at the BATS station [Lohrenz et al., 1992]. When the detrital material sinks below the top hundred meters of the model, it is exported instantaneously within the deep ocean. The flux $E P(z)$ of detrital material is specified by an empirical function proposed by Martin et al. [1987]:

$$
E P(z)=E P(100 \mathrm{~m})\left(\frac{z}{100 \mathrm{~m}}\right)^{-0.858}
$$

Any particulate organic matter that reaches the bottom of the ocean is transformed there to DOC.

[85] The modeled dissolved organic matter is assumed to represent the semilabile component of the dissolved organic pool with a decay rate of the order of 1 year. In the model, DOC is supplied by phytoplankton exudation, zooplankton excretion, and breakdown of detrital material. Observations suggest that bacterial consumption of DOC depends on the availability of nutrients. This consumption appears to be less efficient in the oligotrophic areas [Kirchman et al., 1995]. As proposed by Six and Maier-Reimer [1996], we parameterize this variation by a saturation function:

$$
\begin{aligned}
(\text { Remineralization of DOC })= & \lambda_{\mathrm{DOC}}^{*} \frac{\mathrm{PO}_{4}^{3-}}{K_{\mathrm{DOC}}^{1}+\mathrm{PO}_{4}^{3-}} \\
& \cdot \frac{\mathrm{DOC}}{K_{\mathrm{DOC}}^{2}+\mathrm{DOC}} \text { DOC. }
\end{aligned}
$$

With the chosen parameters the decay rate is reduced by 4 times in oligotrophic areas with phosphate concentrations of about $0.1 \mu \mathrm{mol}$ $\mathrm{L}^{-1}$. Additionally, we assume that remineralization of DOC is reduced for low concentrations of DOC.

[86] Variations of silicate in the photic zone are computed as follows:

$$
\begin{aligned}
\frac{\partial \mathrm{Si}}{\partial t}= & -\left(\frac{\mathrm{Si}}{\mathrm{C}}\right)_{\text {max }} \frac{\mathrm{Si}}{\mathrm{Si}+\mathrm{Si}_{0}} f(T) \frac{\mathrm{Si}}{\mathrm{Si}+\mathrm{Si}_{1}} \\
& \cdot\left[(1-\sigma) g_{P}(P, \mathrm{POC}) Z+m_{P} P+w_{P} P^{2}\right],
\end{aligned}
$$

with

$$
f(T)=\frac{1}{1+\exp [0.1(T-10)]} .
$$

In these equations (A18) and (A19) $T$ is the temperature in ${ }^{\circ} \mathrm{C}$. In equation (A18), silicic acid is assimilatedwith a variable $\mathrm{Si} / \mathrm{C}$ ratio, which depends on the local silicate concentration. This formulation was adopted to simulate higher (lower) $\mathrm{Si} / \mathrm{C}$ ratios in areas where silicate is abundant (lacking) [Brzezinski, 1992]. The maximal Si/C ratio $\left((\mathrm{Si} / \mathrm{C})_{\max }\right)$ has been set according to observations made in the Indian sector of the Southern Ocean [Simon, 1986]. Dissolution of biogenic silicon has been shown to be highly sensitive to temperature [Kamatani, 1982; Hurd and Birdwhistell, 1983]. The rate of biogenic silica dissolution is decreasing with temperature. Consequently, a higher fraction of biogenic silica is likely to be exported below the photic zone in polar regions than in tropical areas. To simulate this temperature-dependent export, we defined a function $f(T)$ similar to Maier-Reimer [1993]. The assimilation of silicic acid is assumed to depend on silicate availability. The halfsaturation constant $\left(\mathrm{Si}_{1}\right)$ has been set to $2 \mu \mathrm{mol} \mathrm{L}{ }^{-1}$ within the range of commonly measured values [Nelson and Tréguer, 1992]. Below $100 \mathrm{~m}$ depth, silicate is released with an exponential penetration depth of $12 \mathrm{~km}$ according to Maier-Reimer [1993].

[87] Acknowledgments. We wish to thank N. Mihalopoulos for his help on the observations. We are grateful to A. J. Kettle for providing us with the databased climatological maps of DMS. We thank E. Maier-Reimer and K. Rodgers for useful comments concerning the manuscript. Support for computations was provided by CEA/DSM and by CNRS/IDRIS. This work was funded by the Environment and Climate Programme of the European Community (ESCOBA-Ocean contract ENV4-CT95-0132).

\section{References}

André, J. M., Télédétection spatiale de la couleur de la mer: Algorithme d'inversion des mesures du Coastal Zone Color Scanner. Applications à l'ètude de la Méditerrannée occidentale, Ph.D. thesis, Univ. Paris VI, Paris, 1990.

Andreae, M. O., The ocean as a source of atmospheric sulfur compounds, in The Role of Air-Sea Gas Exchange in Geochemical Cycling, edited by P. Buat-Menard, pp. 331-362, D. Reidel, Norwell, Mass., 1986.

Andreae, M. O., Ocean-atmosphere interactions in the gobal biogeochemical sulfur cycle, Mar. Chem., 30, 1-29, 1990.

Andreae, M. O., R. J. Ferek, F. Bermond, K. P. Byrd, R. T. Engstrom, S. Hardin, P. D. Houmere, F. Lamarrec, H. Raemdonck, and R. B. Chatfield, 
Dimethylsulfide in the marine atmosphere, J. Geophys. Res., 90, 12,891$12,900,1985$

Andreae, T. W., M. O. Andreae, and G. Sehebeske, Biogenic sulfur emissions and aerosols over the tropical South Atlantic, 1, Dimethylsulfide in seawater and in the atmospheric boundary layer, J. Geophys. Res., 99 , 22,819-22,829, 1994.

Aumont, O., Etude du cycle naturel du carbone dans un modèle 3D de l'océan mondial, Ph.D. thesis, Univ. Paris VI, Paris, 1998.

Aumont, O., J. C. Orr, D. Jamous, P. Monfray, O. Marti, and G. Madec, A degradation approach to accelerate simulations to steady state in a 3-D tracer transport model of the global ocean, Clim. Dyn., 14, 101-116, 1998.

Aumont, O., J. C. Orr, P. Monfray, G. Madec, and E. Maier-Reimer, Nutrient trapping in the equatorial Pacific: The ocean circulation solution, Global Biogeochem. Cycles, 13, 351-371, 1999.

Ayers, G. P., J. P. Ivey, and R. W. Gillett, Coherence between seasonal cycles of dimethylsulfide, methanesulphonate and sulphate in marine air, Nature, 349, 404-406, 1991.

Barthelet, P., et al., Simulations couplées globales des changements climatiques associés à une augmentation de la teneur atmosphérique en $\mathrm{CO}_{2}$, C. R. Acad. Sci. Paris, 326, 677-684, 1998

Bates, T. S., J. D. Cline, R. H. Gammon, and S. R. Kelly-Hansen, Regional and seasonal variations in the flux of oceanic dimethylsufide to the atmosphere, J. Geophys. Res., 98, 2930-2938, 1987.

Bates, T. S., K. C. Kelly, and J. E. Johnson, Concentrations and fluxes of dissolved biogenic gases (DMS, $\mathrm{CH}_{4}, \mathrm{CO}, \mathrm{CO}_{2}$ ) in the equatorial Pacific during the SAGA3 experiment, J. Geophys. Res., 98, 16,969-16,977, 1993.

Belviso, S., R. Morrow, and N. Mihalopoulos, An Atlantic meridional transect of surface water DMS concentrations with $10-15 \mathrm{~km}$ horizontal resolution and close examination of ocean circulation, J. Geophys. Res., 2000

Belviso, S., H. Claustre, and J. C. Marty, Evaluation of the utility of chemotaxonomic pigments as a surrogate for particulate DMSP, Limnol. Oceanogr., 46, 989-995, 2001.

Berresheim, H., Biogenic sulfur emissions from the subantarctic and antarctic oceans, J. Geophys. Res., 92, 13,245-13,262, 1987.

Blain, S., et al., A biogeochemical study of the island mass effect in the context of the iron hypothesis: Kerguelen Islands, Southern Ocean, Deep Sea Res., Part I, 48, 163-187, 2001.

Blanke, B., and P. Delecluse, Low frequency variability of the tropical Atlantic ocean simulated by a general circulation model with mixed layer physics, J. Phys. Oceanogr., 23, 1363-1388, 1993.

Brzezinski, M. A., Cell-cycle effects on the kinetics of silicic acid uptake and resource competition among diatoms, J. Plankton Res., 14, 15111539,1992

Cailliau, C., S. Belviso, M. Goutx, A. Bedo, Y. Park, and E. Charriaud, Sedimentation pathways in the Indian sector of the Southern Ocean during a production regime dominated by regeneration, Mar. Ecol. Prog. Ser., 190, 53-67, 1999

Charlson, R. J., J. E. Lovelock, M. O. Andreae, and S. G. Warren, Oceanic phytoplankton, atmospheric sulfur, cloud albedo and climate, Nature, 326, 655-661, 1987.

Chavez, F. P., K. R. Buck, K. H. Coale, J. H. Martin, G. R. DiTullio, N. A Welschmeyer, A. C. Jacobson, and R. T. Barber, Growth rates, grazing, sinking and iron limitation of equatorial Pacific phytoplankton, Limnol. Oceanogr., 36, 1816-1863, 1991.

Chin, M., D. J. Jacob, G. M. Gardner, M. S. Foreman-Fowler, and P. A. Spiro, A global three-dimensional model of tropospheric sulfate, J. Geophys. Res., 101, 18,667-18,690, 1996.

Claustre, H., The trophic status of various oceanic provinces as revealed by phytoplankton pigment signatures, Limnol. Oceanogr., 39, 1206-1210, 1994.

Claustre, H., and J. C. Marty, Specific plankton biomasses and their relation to primary production in the tropical North Atlantic, Deep Sea Res., Part I, 42, 1475-1494, 1995 .

Cloern, J. E., C. Grenz, and L. Vidergar-Lucas, An empirical model of the phytoplankton chlorophyll:carbon ratio-The conversion factor between productivity and growth rate, Limnol. Oceanogr., 40, 1313-1321, 1995.

Coale, K. H., et al., A massive phytoplankton bloom induced by an ecosystem-scale iron fertilization experiment in the equatorial Pacific Ocean, Nature, 383, 495-501, 1996.

Conkright, M. E., S. Levitus, and T. P. Boyer, World Ocean Atlas, vol. 1, Nutrients, NOAA Atlas NESDIS, vol. 1, 162 pp., Natl. Oceanic and Atmos. Admin., Silver Spring., Md., 1994.

Corn, M., S. Belviso, F. Partensky, N. Simon, and U. Christaki, Origin and importance of picoplanktonic DMSP, in Biological and Environmental Chemistry of DMSP and Related Sulfonium Compounds, edited by R. P. Kiene, pp. 191 - 201, Plenum, New York, 1996.

Curran, M. A. J., G. B. Jones, and H. Burton, The spatial distribution of
DMS and DMSP in the Australasian sector of the Southern Ocean, $J$. Geophys. Res., 103, 16,677-16,689, 1998.

Dadou, I., V. Garçon, V. Andersen, G. R. Flierl, and C. S. Davis, Impact of the North Equatorial Current meandering on the pelagic ecosystem: A modeling approach, J. Mar. Res., 54, 311-342, 1996.

de Baar, H. J. W., J. T. M. de Jong, D. C. E. Bakker, B. M. Löscher, C. Veth, U. Bathmann, and V. Smetacek, Importance of iron for phytoplankton spring blooms and $\mathrm{CO}_{2}$ drawdown in the Southern Ocean, Nature, 373, 412-415, 1995.

De Bruyn, W. J., T. S. Bates, J. M. Cainey, and E. S. Saltzman, Shipboard measurements of dimethyl sulfide and $\mathrm{SO}_{2}$ southwest of Tasmania during the First Aerosol Characterization Experiment (ACE 1), J. Geophys. Res., 103, 16,703-16,711, 1998.

Delecluse, P., M. Imbard, C. Lévy, and G. Madec, OPA-Ocean General Circulation Model, Lab. Océ Anol. Dyn. Clim., Univ. Paris VI, Paris, 1993

DiTullio, G. R., and W. O. Smith, Relationship between dimethylsulfide and phytoplankton pigment concentrations in the Ross Sea, Antarctica, Deep Sea Res., Part I, 42, 873-892, 1995.

Doney, S. C., D. M. Glover, and R. G. Najjar, A new coupled one-dimensional biological-physical model for the upper ocean: Applications to the JGOFS Bermuda Atlantic Time-series Study (BATS) site, Deep Sea Res., Part II, 43, 591-624, 1996

Dugdale, R. C., and F. P. Wilkerson, Silicate regulation of new production in the equatorial Pacific upwelling, Nature, 391, 270-273, 1998.

Erickson, D. J. I., S. J. Ghan, and J. E. Penner, Global ocean-to-atmosphere dimethylsulfide flux, J. Geophys. Res., 95, 7543-7552, 1990.

Falkowski, P. G., Z. Dubinsky, and K. Wyman, Growth-irradiance relationships in phytoplankton, Limnol. Oceanogr., 30, 311-321, 1985.

Fasham, M. J. R., H. W. Ducklow, and S. M. McKelvie, A nitrogen-based model of plankton dynamics in the oceanic mixed layer, J. Mar. Res., 48, $591-639,1990$.

Feichter, J., E. Kjellström, H. Rodhe, F. Dentener, J. Lelieveld, and G. J. Roelofs, Simulation of the tropospheric sulfur cycle in a global climate model, Atmos. Environ., 30, 1693-1707, 1996.

Feldmann, G. C., et al., Ocean color: Availability of the global data set, Eos Trans. $A G U, 70,640-641,1989$.

Frost, B. W., Grazing control of phytoplankton stock in the open subarctic Pacific Ocean: A model assessing the role of mesozooplankton, particularly the large calanoid copepodes Neocalanus spp., Mar. Ecol. Prog. Ser., 39, 49-68, 1987.

Gabric, A. J., N. Murray, L. Stone, and M. Kohl, Modeling production of dimethylsulfide during a phytoplankton bloom, J. Geophys. Res., 98, 22,805-22,816, 1993

Gabric, A. J., G. P. Ayers, and G. C. Sanders, Independent marine and atmospheric model estimates of the sea-air flux of dimethylsulfide in the Southern Ocean, Geophys. Res. Lett., 22, 3521-3524, 1995.

Gabric, A. J., P. H. Whetton, R. Boers, and G. P. Ayers, The impact of simulated climate change on the air-sea flux of dimethylsulphide in the subantarctic Southern Ocean, Tellus, Ser. B, 50, 388-399, 1998.

Gaspar, P., Y. Gregoris, and J. M. Lefevre, A simple eddy kinetic energy model for simulations of the ocean vertical mixing: Tests at station Papa and Long-Term Upper Ocean Study Site site, J. Geophys. Res., 95, $16,179-16,193,1990$

Goose, H., and J. H. Hecq, Modelling the ice-plankton interactions in the Southern Ocean, J. Mar. Syst., 5, 471-484, 1994.

Hatton, A. D., S. M. Turner, G. Malin, and P. S. Liss, Dimethylsulphoxide and other biogenic sulphur compounds in the Galapagos plume, Deep Sea Res., Part I, 46, 617-632, 1998.

Hellermann, S., and M. Rosenstein, Normal monthly windstress over the world ocean with error estimates, J. Phys. Oceanogr., 24, 619-637, 1983.

Holligan, P. M., The physical environment of exceptional phytoplankton blooms in the Northeast Atlantic, Rapp. P. V. Cons. Int. Explor. Mer, 187, 9-18, 1987

Hurd, D. C., and S. Birdwhistell, On producing a more general model for biogenic silica dissolution, Am. J. Sci., 283, 1-23, 1983.

Jacques, G., Some ecophysiological aspects of the antarctic phytoplankton, Polar Biol., 2, 27-33, 1983.

Jochem, F. J., S. Mathot, and B. Quéguiner, Size-fractionated primary production in the open Southern Ocean in austral spring, Polar Biol., $15,381-392,1993$

Kamatani, A., Dissolution rates of silica from diatoms decompositioning at various temperature, Mar. Biol., 68, 91-96, 1982.

Keller, M. D., and W. Korjeff-Bellows, Physiological aspects of the production of dimethylsulfoniopropionate (DMSP) by marine phytoplankton, in Biological Environmental Chemistry of DMSP and Related Sulfonium Compounds, edited by R.P. Kiene et al., pp. 131-153, Plenum, New York, 1996.

Kettle, A. J., et al., A preliminary global data base of sea surface dimethyl 
sulfide (DMS) measurements and a simple model to predict sea surface DMS as a function of latitude, longitude and month, Global Biogeochem. Cycles, 13, 399-445, 1999.

Kirchman, D. L., J. H. Rich, and R. T. Barber, Biomass and biomass production of heterotrophic bacteria along $140^{\circ} \mathrm{W}$ in the equatorial $\mathrm{Pa}-$ cific: Effect of temperature on the microbial loop, Deep Sea Res., Part II, 42, 603-620, 1995.

Lawrence, M. G., An empirical analysis of the strength of the phytoplankton-dimethylsulfide-cloud-climate feedback cycle, J. Geophys. Res., 98, 20,663-20,673, 1993.

Levitus, S., Climatological atlas of the world ocean, NOAA Prof. Pap. 13, 173 pp., U.S. Govt. Print. Off., Washington, D. C., 1982.

Liss, P. S., and L. Merlivat, Air-sea gas exchange rates: Introduction and synthesis, in The Role of Air-Sea Gas Exchange in Geochemical Cycling, NATO ASI, vol. 185, edited by P. Buat-Menard, pp. 113-127, D. Reidel, Norwell, Mass., 1986.

Lohrenz, S. E., G. A. Knauer, V. L. Asper, M. Tuel, A. F. Michaels, and A. H. Knap, Seasonal variability in primary production and particle flux in the northwestern Sargasso Sea: U.S. JGOFS Bermuda Atlantic Timeseries Study, Deep Sea Res., Part A, 39, 1373-1391, 1992.

Longhurst, A., S. Sathyendranath, T. Platt, and C. Caverhill, An estimate of global primary production in the ocean from satellite radiometer data, J. Plankton Res., 17, 1245-1271, 1995.

Madec, G., and M. Imbard, A global ocean mesh to overcome the North Pole singularity, Clim. Dyn., 12, 381-388, 1996.

Maier-Reimer, E., Geochemical cycles in an ocean general circulation model: Preindustrial tracer distributions, Global Biogeochem. Cycles, 7, $645-$ 677, 1993.

Malin, G., S. Turner, P. Liss, P. Holligan, and D. Harbow, Dimethylsulfide and dimethylsulphoniopropionate in the northeast Atlantic during the summer coccolithophore bloom, Deep Sea Res., Part I, 40, $1487-$ $1508,1993$.

Manabe, S., and R. J. Stouffer, Multiple-century response of a coupled ocean-atmosphere model to an increase of atmospheric carbon dioxide, J. Clim., 7, 5-23, 1994.

Marti, O., G. Madec, and P. Delecluse, Comment on net "Net diffusivity in ocean general circulation models with nonuniform grids," J. Geophys. Res., 97, 12,763-12,766, 1992.

Martin, J. H., and S. E. Fitzwater, Iron deficiency limits limits phytoplankton growth in the northeast Pacific subarctic, Nature, 331, 341-343, 1988.

Martin, J. H., G. A. Knauer, D. M. Karl, and W. W. Broenkow, VERTEX: Carbon cycling in the northeast Pacific, Deep Sea Res., Part A., 34, $267-$ 285, 1987.

Meyerdierks, D., B. Bolt, and G. O. Kirst, Spatial and vertical distribution of particulate dimethylsulphoniopropionate (DMSP) during spring in the Atlantic sector of the Southern Ocean, Deep Sea Res., Part II, 44, $283-$ 297, 1997.

Murray, J. W., R. T. Barber, M. R. Roman, M. P. Bacon, and R. A. Feely, Physical and biological controls on carbon cycling in the equatorial Pacific, Science, 266, 58-65, 1994.

Nelson, D. M., and P. Tréguer, Role of silicon as a limiting nutrient to Antarctic diatoms: Evidence from kinetic studies in the Ross Sea iceedge zone, Mar. Ecol. Prog. Ser., 80, 255-264, 1992.

Nguyen, B. C., B. Bonsang, and A. Gaudry, The role of the ocean in the global atmospheric sulfur cycle, J. Geophys. Res., 88, 10,903-10,914, 1983.

Oberhüber, J. M., An atlas based on "COADS" data set, Tech. Rep. 15, Max-Planck Inst. für Meteorol., Hamburg, Germany, 1988.

Pham, M., J. F. Müller, G. P. Brasseur, C. Granier, and G. Mégie, A threedimensional study of the tropospheric sulfur cycle, J. Geophys. Res., 100, 26,061-26,092, 1995 .
Platt, T., C. L. Gallegos, and W. G. Harrison, Photoinhibition of photosynthesis in natural assemblages of marine phytoplankton, J. Mar. Res., 38, 687-701, 1980 .

Sarmiento, J. L., R. D. Slater, M. J. R. Fasham, H. W. Ducklow, J. R. Toggweiler, and G. T. Evans, A seasonal three-dimensional ecosystem model of nitrogen cycling in the North Atlantic euphotic zone, Global Biogeochem. Cycles, 7, 417-450, 1993.

Sciare, J., N. Mihalopoulos, and B. C. Nguyen, Summertime seawater concentrations of dimethylsulfide in the western Indian Ocean: Reconciliation of fluxes and spatial variability with long-term atmospheric observations, J. Atmos. Res., 32, 353-373, 1999.

Simon, V., Le système assimilation régénération des sels nutritifs dans les eaux superficielles de l'Océan Austral, Mar. Biol., 92, 431-442, 1986.

Six, K. D., and E. Maier-Reimer, Effects of plankton dynamics on seasonal carbon fluxes in an ocean general circulation model, Global Biogeochem. Cycles, 10, 559-583, 1996.

Sommer, U., Nitrate and silicate competition among antarctic phytoplankton, Mar. Biol., 91, 345-351, 1986.

Stephens, B. B., R. F. Keeling, M. Heinemann, K. D. Six, R. Murnane, and $\mathrm{K}$. Caldeira, Testing global ocean carbon cycle models using measurements of atmospheric $\mathrm{O}_{2}$ and $\mathrm{CO}_{2}$ concentration, Global Biogeochem. Cycles, 12, 213-230, 1999.

Sullivan, C. W., K. R. Arrigo, C. R. McClain, J. C. Comiso, and J. Firestone, Distributions of phytoplankton blooms in the Southern Ocean, Science, 262, 1832-1837, 1993.

Sverdrup, H. U., On conditions for the vernal blooming of phytoplankton, Rapp. P. V. Cons. Inst. Exelpor. Mer., 18, 287-295, 1953.

Taylor, A. H., A. J. Watson, M. Ainsworth, J. Robertson, and D. R. Turner, A modelling investigation of the role of phytoplankton in the balance of carbon at the surface of the North Atlantic Ocean, Global Biogeochem. Cycles, 5, 151-171, 1991.

Taylor, A. H., R. J. Geider, and F. J. H. Gilbert, Seasonal and latitudinal dependencies of phytoplankton carbon-to-chlorophyll a ratios: Results of a modelling studies, Mar. Ecol. Prog. Ser., 152, 51-66, 1997.

Turner, S. M., P. D. Nightingale, W. Broadgate, and P. S. Liss, The distribution of dimethylsulphide and dimethylsulphoniopropionate in Antarctic waters and sea ice, Deep Sea Res., Part II, 42, 1059-1080, 1995.

Wanninkhof, R., Relationship between wind speed and gas exchange over the ocean, J. Geophys. Res., 97, 7373-7382, 1992.

Watson, A. J., and P. S. Liss, Marine biological controls on climate via the carbon and sulphur geochemical cycles, Philos. Trans. R. Soc. London, 353, 41-51, 1998.

Wolfe, G. V., Uptake and retention of dissolved DMSP by marine bacteria with subsequent degradation during bactivory, in Biological and Environmental Chemistry of DMSP and Related Sulfonium Compounds, edited by R. P. Kiene et al., pp. 277-291, Plenum, New York, 1996.

Yoder, J. A., C. R. McClain, G. C. Feldmann, and W. E. Essaias, Annual cycles of phytoplancton chlorophyll concentrations in the global ocean, Global Biogeochem. Cycles, 7, 181-193, 1993.

O. Aumont, Laboratoire d'Oceanographie Dynamique et de Climatologie, T26-E4, 4 place Jussieu, F-75252 Paris Cedex 05, France. (Aumont@) LODyC.jussieu.fr)

S. Belviso and P. Monfray, Laboratoire des Sciences du Climat et de l'Environnement, DSM, CE Saclay, CEA, L'Orme des Merisiers, Bâtiment 709, F-91191 Gif sur Yvette, Cedex, France. (belviso@1sce.saclay.cea.fr; monfray@1sce.saclay.cea.fr) 